\title{
ABRINDO A CAIXA DE PANDORA DOS NANOMEDICAMENTOS: HÁ REALMENTE MUITO MAIS ‘ESPAÇO LÁ EMBAIXO'
}

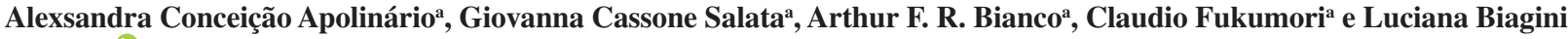 \\ Lopes $^{\text {a, } *,(\mathbb{D})}$ \\ aDepartamento de Farmacologia, Instituto de Ciências Biomédicas, Universidade de São Paulo, 05508-900 São Paulo - SP, Brasil
}

Recebido em 10/09/2019; aceito em 14/01/2020; publicado na web em 20/02/2020

\begin{abstract}
OPENING THE PANDORA'S BOX OF NANOMEDICINE: THERE IS INDEED 'PLENTY OF ROOM AT THE BOTTOM'. Limitations of conventional treatment and dosage forms prompted the investigation of novel approaches that combine efficacy, selectivity and fewer adverse effects. These are the main promises of nanomedicine, generally defined as the application of nanotechnology to the biomedical field. Despite the considerable advances over the years and the large number of publications resulting from the growth of nanomedicine, there are still many hurdles and unknown factors limiting its successful translation from promise to reality. These factors range from the lack of standardization in the terminology and regulations, to the lack of understanding of interactions between nanocarriers and the biological system, and their influence on drug pharmacodynamics. In this manuscript, we aim at presenting and discussing concepts and terminologies used in the nanomedicine field and examining the main types of nanocarriers and their effects to modulate biological barriers and aid drug transport, bioavailability and targeting.
\end{abstract}

Keywords: nanocarriers; nanomedicine; biological barriers; nanopharmacology.

\section{INTRODUÇÃO}

O desenvolvimento de produtos baseados em nanotecnologia pode parecer revolucionário em algumas áreas, mas a aplicação da nanotecnologia não é tão nova. Já no século IV dC, a famosa taça de Licurgo confeccionada pelos romanos exibia cores diferentes dependendo da iluminação, efeito atribuído posteriormente à presença de pequenas proporções de nanopartículas de ouro e prata dispersas em forma coloidal em todo o material de vidro. ${ }^{1} \mathrm{O}$ conceito geral de nanotecnologia foi introduzido pela primeira vez há seis décadas, em 1959, pelo físico Richard Feynman em uma palestra intitulada "Há mais espaço lá embaixo" (originalmente There is Plenty of Room at the Bottom), na qual foi sugerida a manipulação de objetos em dimensões atômicas e, posteriormente, lançou para comunidade científica o conceito de dispositivos na escala nanométrica pela primeira vez em um artigo. ${ }^{2}$

Décadas depois, mesmo com o aumento do número de medicamentos baseados em nanotecnologia registrados e disponibilizados para fins terapêuticos, ainda há muitas lacunas na área, especialmente quando comparamos com o grande número de publicações científicas disponíveis, sendo que até agências regulatórias como a US Food and Drug Administration (FDA) apresentam poucos guidelines finalizados e lançaram por enquanto apenas um rraft. $^{3}$ Além disso, as promessas da nanotecnologia, especialmente para a terapia de doenças que podem evoluir com gravidade como o câncer, ainda parecem estar dentro de uma caixa de Pandora. ${ }^{4-7}$ Desde os anos 90 e até hoje, as pesquisas prometem maior precisão na ação farmacológica de fárma$\cos$ nanoencapsulados, ${ }^{8}$ efeito de permeação e retenção aumentados em tecidos acometidos por tumores e outros processos inflamatórios, ${ }^{9}$ maior permeação transdémica, ${ }^{10}$ capacidade de ultrapassar a barreira hematoencefálica (BHE), ${ }^{11}$ entre outras vantagens. Várias delas ainda parecem longínquas do ponto de vista clínico.

Outro aspecto perceptível é a falta de padronização dos métodos de caracterização dos carreadores na escala nanométrica, especialmente quando comparados aos medicamentos tradicionais

*e-mail: lublopes@usp.br como cápsulas ou comprimidos que contam com métodos disponíveis em compêndios como as farmacopeias. Isso provém do fato de que a regulamentação de nanomedicamentos ainda é muito incipiente. As primeiras diretrizes foram lançadas pela $F D A$ em $2014,{ }^{12}$ e mais recentemente em $2017,{ }^{3}$ foi publicada uma minuta de um Guideline que propõe uma padronização quanto à caracterização destes produtos, bem como uma compreensão do uso e aplicação pretendidos, além da investigação dos atributos que estão relacionados à qualidade, segurança e eficácia. A FDA já revisou e aprovou diversos produtos que se utilizam da nanotecnologia e, baseado nos avanços científicos que vêm permitindo melhor manipulação, produção e visualização de nanoestruturas, espera-se um aumento na utilização da tecnologia em dispositivos médicos, medicamentos, cosméticos e alimentos. Assim, uma preocupação da agência é desenvolver e melhorar procedimentos para detecção, quantificação e regulação de nanomateriais em produtos e amostras biológicas, bem como seu impacto no meio ambiente, como descrito em seu website (https:// www.fda.gov/about-fda/nctr-research-focus-areas/nanotechnology) com a criação da 'NCTR/ORA Nanotechnology Core Facility'. A necessidade de criar definições para caracterizar a presença de nanomateriais em produtos para finalidades regulatórias e legislativas também foi enfatizada pela European Comission (EC, ramo executivo da União Européia), mas, embora uma definição seja fornecida, não foi estabelecida classificação de risco ou segurança. ${ }^{13}$ Outra iniciativa importante nesse aspecto foi a NANoREG (ver sessão "Regulamentação para nanomedicamentos"). Ainda existem inúmeras dúvidas e discussões quanto à definição de atributos de qualidade para tais produtos. ${ }^{14}$

Aliado à falta de padronização prática, há uma pletora de termos que vêm sendo usados indiscriminadamente com o prefixo nano, muitas vezes colocados como sinônimos ou mesmo como diferentes, mas sem nenhum padrão conceitual. Por exemplo, nanopartículas podem ser divididas em nanocápsulas e nanoesferas quando se refere àquelas de composição polimérica, ${ }^{15}$ no entanto existem também as nanopartículas lipídicas, e há autores que definem nanocarreadores vesiculares, como lipossomas e polimerossomas, como nanopartículas também. A confusão conceitual não para por aí: um exemplo 
clássico que pode confundir muitos são os termos microemulsão e nanoemulsão, uma vez que as microemulsões têm fase dispersa de dimensões inferiores que a microescala, às vezes até mesmo inferiores às nanoemulsões. ${ }^{16}$

Neste trabalho, nós objetivamos discutir de maneira crítica e uniformizar alguns conceitos que fundamentam a aplicação de nanotecnologia para veiculação e liberação de fármacos, bem como descrever alguns dos principais nanocarreadores que vem sendo estudados e disponibilizados para uso clínico e alguns dos efeitos moduladores de barreiras biológicas que possibilitam melhor o transporte, biodisponibilidade e direcionamento de fármacos.

\section{Terminologias e conceitos}

As terminologias 'nano'

A Figura 1 compara diferentes micro e nanoestruturas e destacamos a faixa de escala nanométrica em comparação com células e algumas biomoléculas.

A FDA não estabeleceu definições precisas para os termos "nanotecnologia”, "nanomaterial", "nanoescala" ou outros relacionados. No entanto, a agência descreveu considerações sobre nanotecnologia em seu guia ${ }^{12}$ em junho de 2014 , assim ao considerar se um produto a ser regulamentado envolve a aplicação de nanotecnologia, a agência levantará os seguintes pontos:

1) "se um material ou produto é projetado para ter pelo menos uma dimensão externa, ou uma estrutura interna ou de superfície, na faixa de nanoescala (aproximadamente $1 \mathrm{~nm}$ a $100 \mathrm{~nm}$ )". Aqui é importante ter em mente que apenas uma dimensão do material ou produto pode ser considerada no registro. Em fibras para curativo, ${ }^{17}$ por exemplo, embora apenas o diâmetro esteja na escala nanométrica, o produto pode ser considerado um nanomedicamento.

2) "se um material ou produto é projetado para exibir propriedades ou fenômenos, incluindo propriedades físicas ou químicas ou efeitos biológicos que são atribuíveis a sua dimensão (s), mesmo se essas dimensões estejam fora da faixa de nanoescala, até um micrômetro $(1.000 \mathrm{~nm})$ ". Essa definição permite expandir o conceito para alguns carreadores que possuem mais de $100 \mathrm{~nm}$ e que ainda demostrem propriedades inerentes à nanoescala. Por exemplo, pesquisadores demonstraram que um tipo nanocarreador polimérico chamado polimerossoma (ver seção nanocarreadores) com tamanho de $400 \mathrm{~nm}$ foi capaz de atravessar poros de $50 \mathrm{~nm}$ intactos na mesma proporção que um nanocarreador de mesma composição (micelas) com tamanho $85 \mathrm{~nm}$; no entanto, os maiores exibiram uma taxa de permeação mais rápida em comparação aos menores devido à sua maior flexibilidade. ${ }^{18}$

Outra problemática advém do uso do prefixo 'nano'que vem sendo muito utilizado na área farmacêutica para designar carreadores para fármacos em escala nanométrica, mas que tem sido usado indiscriminadamente, muitas vezes de maneira desnecessária ou redundante. Um exemplo é o termo nanomicela; poderia ser utilizado apenas o termo "micela", uma vez que são estruturas de autoagregação de dimensão nanométrica. Exemplos semelhantes são os termos nanovesícula ou nanolipossoma para os lipossomas unilamelares pequenos, ${ }^{19}$ pois seu tamanho nanométrico já é bem descrito.

Uma breve consulta à base de dados Web of Science também sugere que diferentes termos são usados com mesmo sentido dependendo da área; por exemplo, as terminologias nanomedicamento (do inglês nanomedicine) e nanoformulação têm sentido similar e ambas são mais usadas na área farmacêutica. Já nanocarreador é uma das construções mais usadas em artigos. Nanosistema, por outro lado, é um termo mais geral e amplamente usado na área das ciências de materiais, mas também pode fazer uma referência a estudos que levam em consideração não apenas aspectos farmacológicos, mas fenômenos físico-químicos. Nanoestrutura é uma palavra que pode se referir ao arranjo moléculas, como DNA e RNA, mas pode ser colocada também como um termo geral quando não há uma definição do tipo exato de

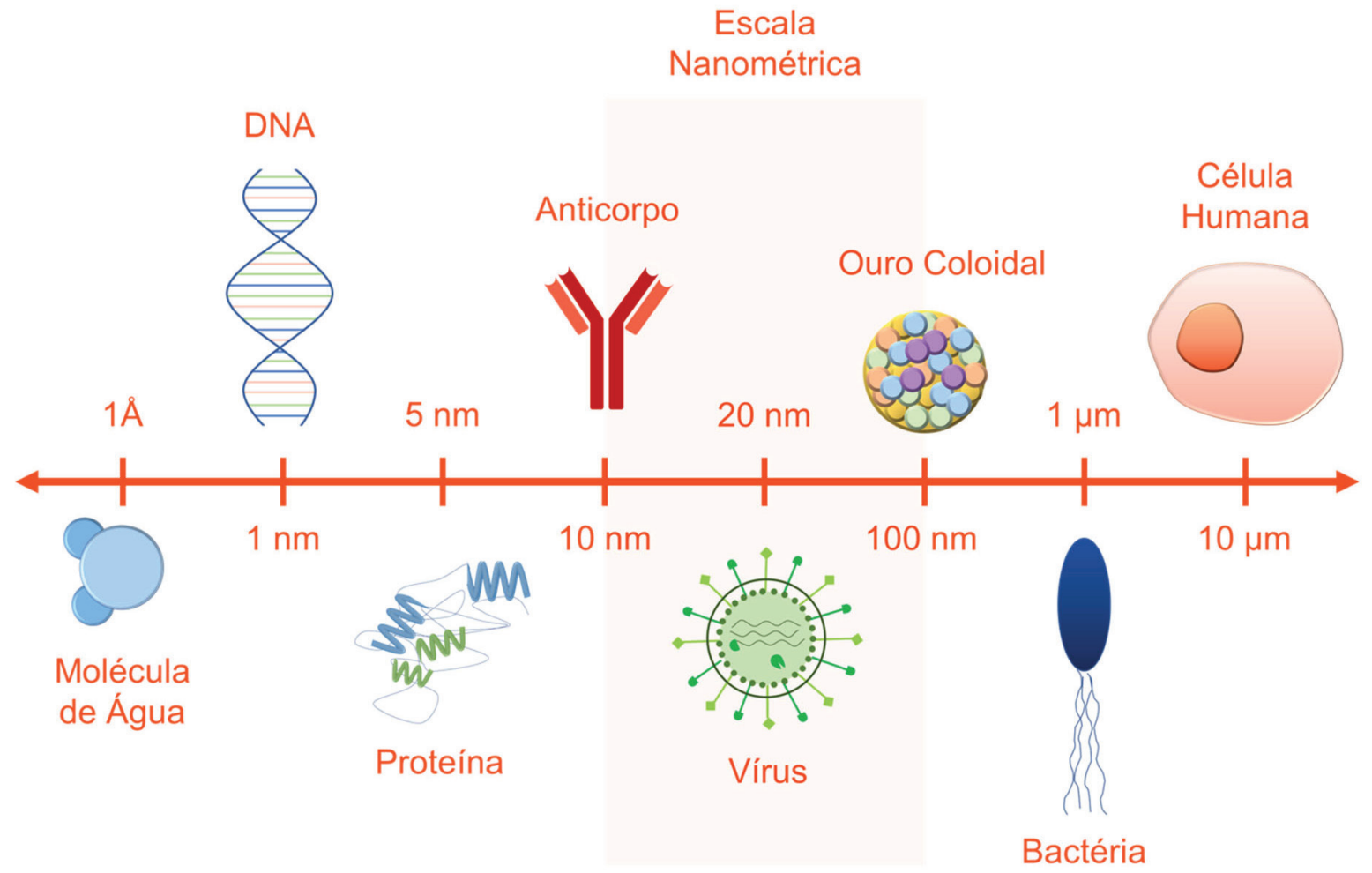

Figura 1. Inserção da nanoescala em comparação com as dimensões atômicas das moléculas pequenas como a da água, passando pelas macromoléculas biológicas como proteínas e estruturas virais até a escala micrométrica das células 
estrutura; um exemplo são as nanoestruturas formadas a partir da auto-organização de copolímeros em solução aquosa, fenômeno que pode originar vesículas, micelas ou túbulos.

Aqui usaremos o termo nanocarreador (NC) quando nos referimos a nanoestruturas usadas para encapsulação e liberação de fármacos como lipossomas, nanopartículas lipídicas solidas, nanoemulsões e afins; e nanomedicamentos quando fazemos menção à formulação final baseada em nanocarreadores, a qual pode ser liofilizada, dispersa em um gel, ou mesmo aprovada na forma como obtida para uso como medicamento.

\section{Conceitos clássicos em nanomedicina}

Como mencionado anteriormente, o conceito de nanotecnologia no registro de medicamentos envolve não apenas a escala, mas as diferentes caraterísticas resultantes de seu tamanho que resultariam em um melhor desempenho terapêutico do produto. Desse modo, o perfil diferenciado de liberação de fármacos a partir nanocarreadores bem como a distribuição distinta (especificidade e/ou penetração em tecidos) alcançada fundamenta conceitos biofarmacêuticos que são, na maioria das vezes, relatados como vantagens dos nanocarreadores. Fala-se então em um campo chamado de nanofarmacologia, o qual se baseia incialmente em perfis farmacocinéticos modulados como, por exemplo, aumento de biodisponibilidade e/ou meia-vida e alterações nas ações dos fármacos, como alterações farmacodinâmicas que resultem em maior eficácia. A Tabela 1 descreve alguns destes conceitos.

\section{Nanocarreadores: tipos, semelhanças e distinções}

Uma vez que já foram descritos alguns dos conceitos que fundamentam a nanotecnologia na área de liberação de fármacos, é importante conhecer alguns dos NC mais amplamente descritos em publicações científicas, sendo alguns já usados clinicamente. A Figura 2 exibe a representação esquemática desses nanocarreadores, bem como os descreve em ordem cronológica da sua descrição na literatura.

Os NC não apresentam uma classificação definida e muitos pesquisadores usam a composição como ponto de partida. Nesse sentido, há NC lipídicos e NC poliméricos, mas um mesmo NC também pode ter composição variadas, contendo polímeros e lipídeos ao mesmo tempo, ${ }^{30}$ bem como pode haver combinações de nanocarreadores no mesmo sistema de liberação. ${ }^{31}$ Incluímos uma breve descrição de alguns NC abaixo.

\section{Lipossomas}

Lipossomas (Figura 3) são estruturas vesiculares com interior aquoso delimitado por uma (unilamelares) ou mais (multilamelares) bicamadas lipídica concêntrica que podem conter colesterol para aumentar a rigidez. ${ }^{32} \mathrm{O}$ tipo de lipídio usado pode conferir furtividade quando peguilados ou mesmo responsividade para aqueles que são sensíveis a mudanças de temperatura ou $\mathrm{pH}$ (estes $\mathrm{NC}$ responsivos são chamados de inteligentes e serão discutidos adiante). Essas nanoestruturas foram relatadas pela primeira vez por Bangham et al.,${ }^{33} \mathrm{em}$ 1965. É importante ressaltar que lipossomas podem ser produzidas na escala micrométrica para simular células em estudos de biofísica, ${ }^{34}$ no entanto, aqui a referência será apenas como NC para fármacos. Uma das principais vantagens dos lipossomas é a possibilidade de encapsulação de agentes de diagnóstico ou terapêuticos hidrofílicos e hidrofóbicos, proporcionando um maior "carregamento" de fármaco por $\mathrm{NC}$ e protegendo os agentes encapsulados dos processos metabólicos.

É possível modificar lipossomas com a adição de diferentes componentes que desencadeiam novas propriedades para estas estruturas. Por exemplo, transferssomas são lipossomas altamente flexíveis
Tabela 1. Conceitos que fundamentam a nanofarmacologia

\begin{tabular}{ll}
\hline \multicolumn{1}{c}{ Conceitos } \\
\hline Efeito burst ou de & $\begin{array}{l}\text { Termo que se refere à liberação intensa e rápida do } \\
\text { fajada }\end{array}$ \\
$\begin{array}{l}\text { fármaco do NC, que pode ocorrer nos primeiros } \\
\text { corrente sanguínea. }{ }^{20}\end{array}$
\end{tabular}

Efeitos de permeação

e retenção (EPR)

Efeito que ocorre em tecidos tumorais sólidos e/ aumentados ou sítios inflamatórios em que o nanocarreador pode permear passivamente através dos vasos sanguíneos, que frequentemente apresentam maior permeabilidade nesses tecidos. Adicionalmente, como espaço intersticial do tumor apresenta uma filtração linfática suprimida, ocorre o acúmulo no sítio tumoral com liberação dos fármacos. ${ }^{21}$

\begin{tabular}{ll}
\hline Coencapsulação & $\begin{array}{l}\text { Encapsulação de múltiplos agentes com finali- } \\
\text { dade terapêutica e/ou de diagnóstico no mesmo } \\
\text { nanocarreador. }\end{array}$
\end{tabular}

\section{Passagem}

pela barreira

hematoencefálica

Refere-se a habilidade de atravessar a barreira hematoencefálica, que é altamente seletiva e separa a circulação sistêmica do sistema nervoso central (SNC). É fundamental para tratamento de lesões, distúrbios e/ou infecções que acometem o SNC. ${ }^{11,23}$

\begin{tabular}{ll}
\hline $\begin{array}{l}\text { Terapia com alvo } \\
\text { intracelular/ uptake } \\
\text { celular }\end{array}$ & $\begin{array}{l}\text { Nanocarreador passível de sofrer internalização } \\
\text { celular ou em organelas celulares por meio de } \\
\text { processos variados, como endocitose, e permitir a } \\
\text { liberação intracelular do fármaco. }{ }^{24}\end{array}$ \\
\hline Escape endossomal & $\begin{array}{l}\text { Na endocitose, os nanocarreadores são tipicamente } \\
\text { aprisionadas em estruturas vesiculares intracelu- }\end{array}$ \\
& $\begin{array}{l}\text { lares como as vesículas endossomais, o que pode } \\
\text { levar à sua degradação. Estratégias para escapar } \\
\text { desse processo constituem o escape endossoma25 }\end{array}$ \\
& $\begin{array}{l}\text { e são de grande importância para a eficácia do } \\
\text { fármaco. }\end{array}$
\end{tabular}

Furtividade Capacidade de evadir-se do sistema imunológico, evitando respostas e/ou eventos imunológicos que potencialmente eliminariam o NC. ${ }^{26}$

Fármaco encapsulado Fármaco carreado dentro da nanoestrutura, por exemplo, no interior ou dentro da bicamada de vesículas, aprisionado dentro da matriz polimérica de nanopartículas ou no núcleo oleoso de nanocápsulas, sendo que a liberação requer que o fármaco se difunda para fora da nanoestrutura. ${ }^{27}$

Fármaco adsorvido Fármaco localizado externamente ao nanocarreador, geralmente mantendo algum tipo de interação físico-química com ele. Por exemplo, na superficie de vesículas e nanoesferas.

\begin{tabular}{ll}
\hline $\begin{array}{l}\text { Eficiência de } \\
\text { encapsulação }\end{array}$ & $\begin{array}{l}\text { Porcentagem de fármaco adsorvido ou encap- } \\
\text { sulado em relação ao total de fármaco usado na } \\
\text { formulação. }\end{array}$ \\
\hline $\begin{array}{l}\text { Eficiência de } \\
\text { carregamento/ loading }\end{array}$ & $\begin{array}{l}\text { Porcentagem de massa de fármaco encapsulada em } \\
\text { relação à massa final de nanocarreador. }\end{array}$ \\
\hline Biocorona & $\begin{array}{l}\text { Camada ou "coroa" biomolecular firmemente } \\
\text { aderida a superfície do NC oriundas da adsorção } \\
\text { de proteínas e outras biomoléculas em ambientes } \\
\text { fisiológicos. }\end{array}$ \\
\hline Teranóstica & $\begin{array}{l}\text { Uso de nanocarreadores para diagnosticar e/ou } \\
\text { monitorar uma condição patológica do paciente } \\
\text { fornecendo simultaneamente, um tratamento. }{ }^{29}\end{array}$ \\
\hline
\end{tabular}

devido à presença de moléculas de tensoativos. ${ }^{36}$ Etossomas contêm de $20-45 \%$ de etanol que age como promotor de permeação cutânea. ${ }^{36}$ Transetossomas são nanoestruturas similares aos lipossomas, com a 


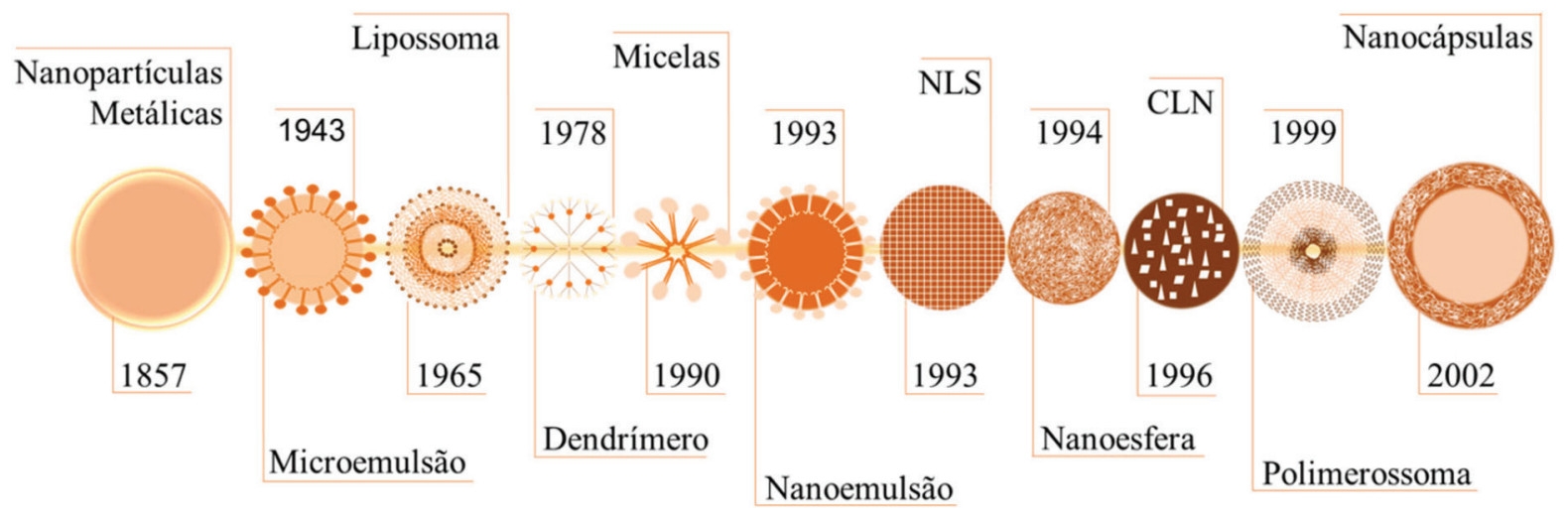

Figura 2. Principais nanocarreadores dispostos em ordem cronológica. $N L S=$ nanocarreador lipídico sólido; CLN = carreador lipídico nanoestruturado

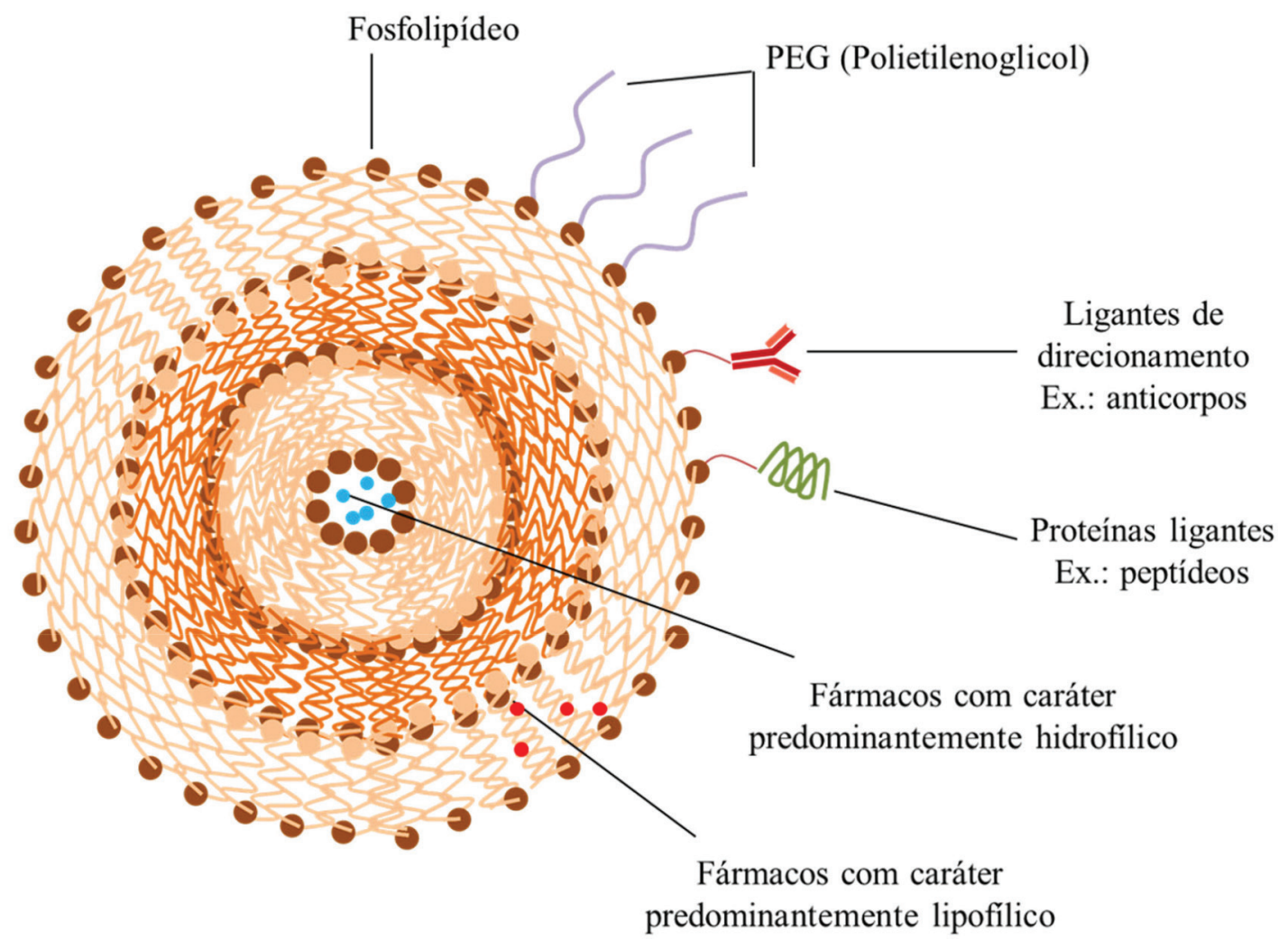

Figura 3. Representação da estrutura de lipossomas convencionais, lipossomas peguilados com moléculas de polietilenoglicol na superfície, lipossomas sítio-dirigidos com a presença de macromoléculas como proteínas, aptâmeros ou "small molecules" como folatos e lipossomas multifuncionais, que poderiam ter função teranóstica por exemplo. Baseado e adaptado de: https://www.mdpi.com/1420-3049/23/4/90, Olusanya et al., ${ }^{35}$ um artigo Open Access distribuído pelos termos da Creative Commons Attribution License que permite uso, distribuição e reprodução

presença de $20-45 \%$ de etanol e moléculas tensoativas, combinando assim as vantagens dos etossomas e transferossomas. ${ }^{36}$

Um dos principais inconvenientes dos lipossomas convencionais é o rápido clearance, devido à adsorção de proteínas (biocorona) para aqueles não peguilados, bem como a fragilidade osmótica ${ }^{37} \mathrm{~A}$ peguilação é o processo pelo qual as cadeias de polietilenoglicol estão ligadas na superfície dos lipossomas, o que leva a um prolongamento no tempo de circulação sanguínea dos lipossomas em comparação com as preparações lipossomais convencionais, e aumento da meia-vida. Além disso, esses NC são menos extensivamente capturados pelas células do sistema reticuloendotelial e têm uma tendência reduzida de liberar o fármaco enquanto circula e demonstram ter melhor EPR. ${ }^{38}$

Os lipossomas sítio-dirigidos permitem o chamado direcionamento ativo para receptores celulares através de moléculas ligadas à superfície que dirigem a captação de fármaco para alvos específicos, como células tumorais ou células estromais associadas a tumores, e assim podem aumentar a seletividade da distribuição dos fármacos. ${ }^{38}$

Os principais métodos de produção de lipossomas descritos são hidratação do filme lipídico e injeção de etanol. No primeiro, se promove a hidratação com água ou tampão de um filme lipídico sob agitação, o qual é formado após a dissolução em solvente orgânico, seguida da evaporação do solvente. Os lipossomas produzidos por esta técnica resultam em um conteúdo heterogêneo com vesículas multilamelares com mais de $1 \mu \mathrm{m}$ de diâmetro, requerendo etapas adicionais de preparação, como sonicação ou extrusão, para reduzir e uniformizar o tamanho das vesículas. ${ }^{39}$ Apesar da ampla aplicação, a preparação de lipossomas por meio de hidratação do filme, em escala de laboratório, é possível, mas essa técnica raramente se mostra adequada para grandes escalas. Nesse sentido, a injeção de etanol permite a obtenção de lipossomas pequenos com distribuição estreita 
simplesmente injetando uma solução lipídica etanólica em água (ou seja, em uma única etapa, sem extrusão ou sonicação). ${ }^{39}$

\section{Polimerossomas e micelas poliméricas}

Os polimerossomas são considerados análogos estruturais dos lipossomas, uma vez que são vesiculares assim como os lipossomas, mas a bicamada é polimérica, formada a partir da autoagregação de copolímeros anfifílicos. Ou seja, são formados por blocos com caráter polar e apolar unidos covalentemente e que se autoagregam em ambiente aquosos, resultando em diferentes nanoestruturas dependendo da proporção destes blocos. Originalmente, foram descritas em 1999 por Discher et al., ${ }^{40}$ e foram consideradas vesículas mais robustas quanto às propriedades físico-químicas se comparadas aos lipossomas em razão da composição polimérica.

Para copolímeros com porção hidrofílica formada por PEG, pode-se ainda inferir o tipo de nanoestrutura formada a partir do parâmetro $f(0<f<1)$ e que representa o volume da fração hidrofílica, como descrito na Tabela 2 adaptada de Apolinário et al. ${ }^{41}$

Tabela 2. Classificação teórica dos sistemas formados a partir do valor da fração hidrofílica $(f)$

\begin{tabular}{cc}
\hline Volume da fração hidrofílica $(f) \%$ & Nanoestruturas formadas \\
\hline $40<f<25$ & Polimerosssomos \\
$50<f<40$ & Micelas poliméricas cilíndricas \\
\hline
\end{tabular}

Os polimerossomas (Figura 4) são elaborados pelos mesmos métodos usados para elaboração de lipossomas na maioria das vezes, mas em razão das características físico-químicas diferenciadas de alguns polímeros, como alta temperatura de transição vítrea que dificulta a extrusão, ${ }^{42}$ apresentam algumas limitações, como trabalhos que relatam tempo de hidratação do filme de um mês para que ocorra a formação destas vesículas. ${ }^{43}$ Às vezes, há a necessidade de técnicas específicas para encapsulação, como a eletroporação descrita por Wang et al.,${ }^{44}$ que consiste na formação provisória de poros na bicamada destas vesículas, permitindo a encapsulação de moléculas grandes, como proteínas terapêuticas.

As micelas poliméricas também são nanoestruturas formadas a partir da autoagregação de copolímeros anfífilicos ${ }^{41} \operatorname{com}$ a formação de um core hidrofóbico rodeado por porção hidrofílica. Dependendo da proporção entre os blocos hidrofílicos e hidrofóbicos, método de produção e fatores externos como temperatura, a autoagregação pode acontecer preferencialmente em vesículas ou micelas. É importante ressaltar que tensoativos não-poliméricos também podem formar micelas.

Dois mecanismos têm sido propostos para explicar a formação dos polimerossomas, o primeiro mecanismo fundamenta que ocorre o crescimento de micelas em bicamadas que se auto-organizam em vesículas enquanto o segundo mecanismo acrescenta que ocorreria a difusão de solvente dentro destas micelas e posteriormente a formação das vesículas como descrito por Bleul et al. ${ }^{45}$ Desse modo, tem sido aceito que as micelas esféricas seriam os autoagregados dos quais se formariam os demais tipos de agregados, como micelas cilíndricas, vesículas entre outros. ${ }^{46}$

\section{Microemulsões e nanoemulsões}

Micro e nanoemulsões (Figura 5) são dispersões coloidais que, embora apresentem similaridade do ponto de vista de composição e estrutura microscópica, apresentam diferenças muito importantes que resultam em diferentes comportamentos físico-químicos. ${ }^{16}$

Várias definições para microemulsões já foram propostas, sendo que a mais amplamente aceita foi introduzida por Danielsson e

\section{Copolimero anfifilicos}

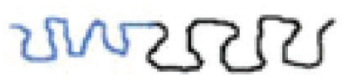

Copolimero dibloco

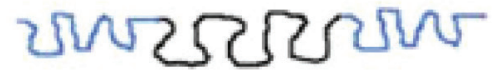

Copolimero tribloco

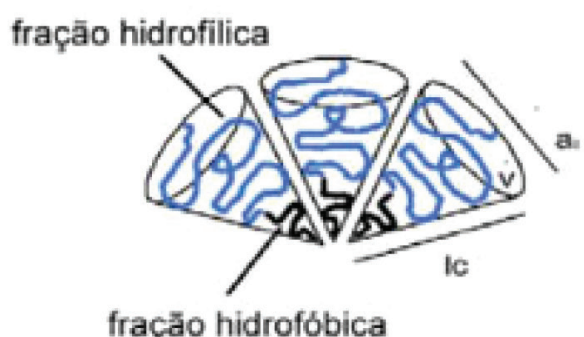

fração hidrofobica
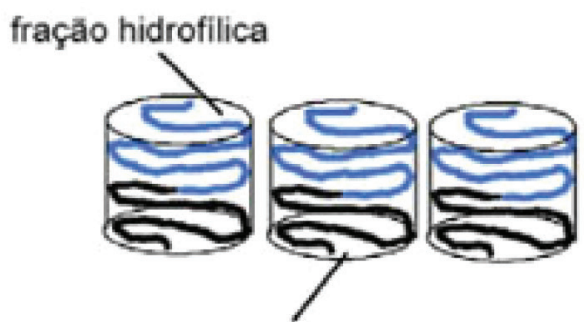

fraçăo hidrofóbica

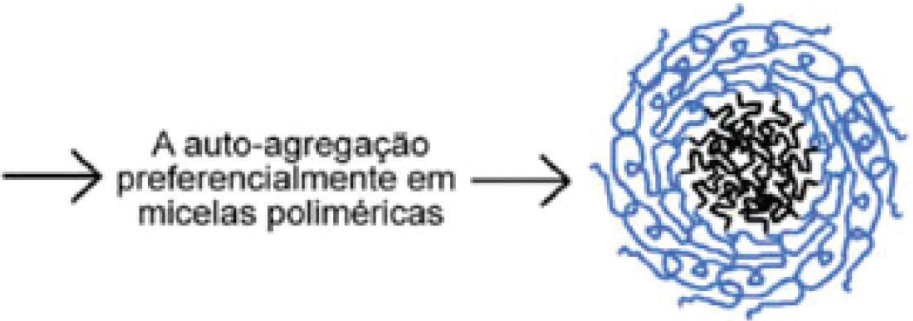

A auto-agregaçăo preferencialmente em polimerossomos
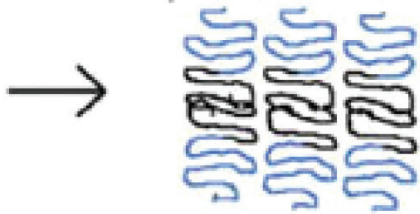

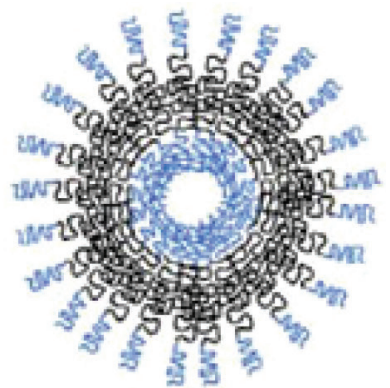

Figura 4. Representação da autoagregação de estruturas poliméricas formando polimerossomas. Reproduzido de http://quimicanova.sbq.org.br/detalhe_artigo. asp?id=6602, Apolinário et al. ${ }^{41}$ um artigo Open Access distribuído pelos termos da Creative Commons Attribution License que permite uso, distribuição e reprodução 
Lindman, em 1981, ${ }^{47}$ que as descreveram como sistemas líquidos, opticamente isotrópicos e termodinamicamente estáveis, formados por água (ou fase polar), óleo (ou fase apolar) e um ou mais tensoativos. Hoar e Schulman introduziram pela primeira vez o conceito de microemulsões em 1943 a partir de uma preparação de leite com hexano ${ }^{48}$ embora o termo "microemulsões" seja atribuído a Schulman e colaboradores que a usaram em artigos da década de $50 .{ }^{49}$ No entanto, dificuldades de caracterização e discussões acerca da predição de sua estrutura geraram disputas de nomenclatura, e microemulsões já foram conhecidas como "dispersões transparentes de óleo e água", "emulsão micelar transparente", "solução micelar" e "micelas intumescidas", entre outros termos. ${ }^{49}$

As microemulsões podem se organizar em sistemas de fase oleosa (ou orgânica) dispersa em fase aquosa (ou polar), chamadas genericamente de microemulsões óleo-em-água (o/a) ou o contrário $(\mathrm{a} / \mathrm{o}) .{ }^{50,51}$ Além dessas, existem também as microemulsões bicontínuas, nas quais as fases aquosas e oleosas coexistem como canais contínuos, entrelaçados, mas separados por uma interface de tensoativo. ${ }^{52,53}$ A estrutura deste tipo de microemulsão ainda não foi claramente elucidada e é muito discutida, sendo sua existência, uma das responsáveis pelas numerosas definições propostas para microemulsões. Foi sugerido um paralelo com fases líquido-cristalinas liotrópicas, mas atualmente acredita-se que as microemulsões bicontínuas não apresentam a ordem característica dos cristais líquidos. ${ }^{52}$ Sendo termodinamicamente estáveis, a formação de microemulsões pode ocorrer espontaneamente desde que respeitada a propriedade fundamental de tensão interfacial ultrabaixa, a qual é promovida pela presença de tensoativo (ou combinação de tensoativos) geralmente em elevadas concentrações. ${ }^{47}$

Microemulsões são frequentemente confundidas com nanoemulsões na literatura. Parte da confusão provém do uso dos prefixos "nano" e "micro", o que implica a existência de uma diferença de tamanho de 1000 vezes entre elas, muito embora as gotículas desses sistemas possam apresentar diâmetro semelhante. No entanto, como as microemulsões foram descritas cronologicamente antes, o termo difundiu-se e popularizou-se entre pesquisadores antes da introdução das nanoemulsões e da diferenciação desses sistemas. Além disso, o fato de nano e microemulsões serem descritas de maneira muito similar dificulta sua diferenciação. Entretanto, a diferença não está no tamanho; uma das diferenças fundamentais é que as nanoemulsões não são termodinamicamente estáveis e, portanto, podem sofrer separação de fases ao longo do tempo, embora geralmente apresentem boa estabilidade cinética. ${ }^{54-56}$

Assim sendo, ao contrário das microemulsões, abordagens para produção de nanoemulsões geralmente envolvem métodos com emprego de alta energia, podendo ser por meio de dispositivos conhecidos como "homogeneizadores" capazes de gerar forças disruptivas intensas que promovem a emulsificação entre as fases de óleo e água, formando minúsculas gotículas. Podemos citar como exemplo homogeneizadores com válvulas de alta pressão, microfluidificadores e sistemas de cavitação por ultrassom. ${ }^{55,57}$

Dependendo da proporção entre seus componentes, microemulsões podem existir como uma única fase (preferencial na área farmacêutica como sistemas para liberação de fármacos), na qual todos os componentes encontram-se solubilizados, ou coexistir em equilíbrio com excesso de fase polar ou apolar em sistemas multifásicos (sistemas Winsor). ${ }^{49}$ A presença de microemulsões coexistindo com gotículas maiores em nanoemulsões e em emulsões convencionais também foi recentemente proposta. ${ }^{58}$ Além das microemulsões, podem ainda ser formados cristais líquidos liotrópicos..$^{59,60}$ Esses consistem em moléculas anfifílicas e solventes que podem se organizar em mesofases hexagonais, cúbicas, lamelares e outros. ${ }^{61}$ Entre esses sistemas, as mesofases hexagonais cúbicas e hexagonais reversas são as mais extensivamente investigadas por sua capacidade de sustentar a liberação de uma ampla gama de compostos bioativos, de fármacos de baixo peso molecular até proteínas, peptídeos e ácidos nucleicos. ${ }^{62-64}$

O comportamento de fase das microemulsões é descrito graficamente por diagramas de fase ternários, elaborado a partir da combinação de três componentes (tensoativo, fase oleosa e fase aquosa) e pseudoternários (os quais apresentam dois tipos de tensoativos, sendo um chamado de cotensoativo, normalmente um álcool de cadeia curta ou média). ${ }^{53,65}$ Esses diagramas especificam as fases formadas sob várias condições experimentais determinadas e definem precisamente suas composições. Uma maneira conveniente de representar

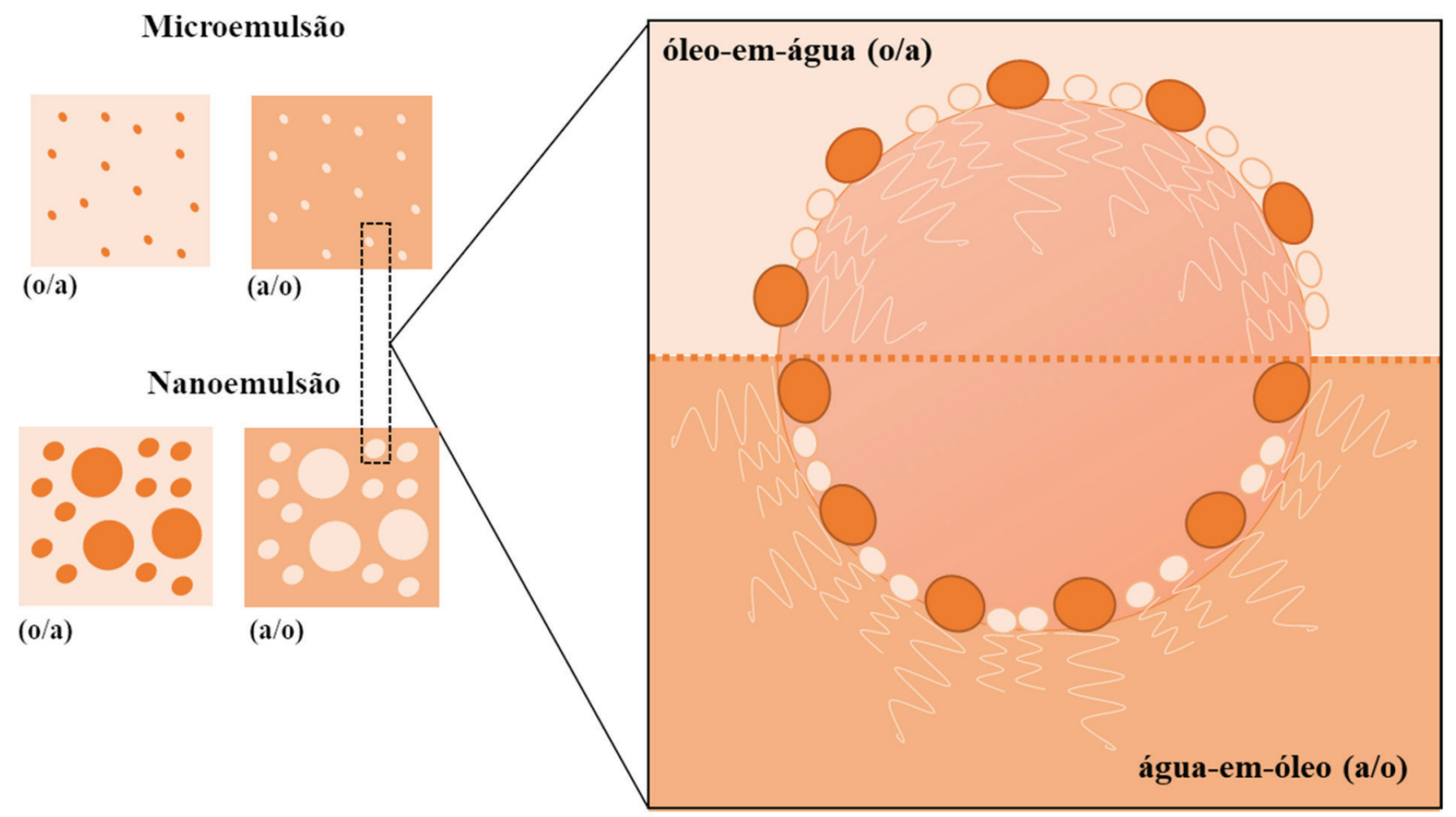

Figura 5. Representação microscópica da nanoestruturação de micro e nanoemulsões com destaque para o fato de que as nanoemulsões podem conter gotículas de tamanhos maiores que as microemulsões 
as possíveis composições de sistemas de microemulsão é construir diagramas de fase como triângulos equiláteros ${ }^{65}$ (Figura 6).

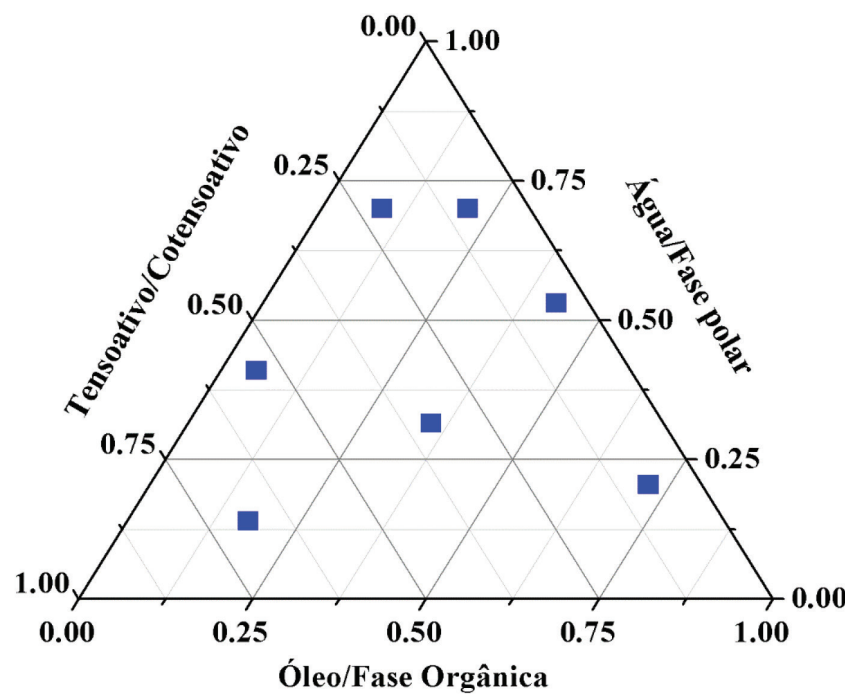

Figura 6. Representação hipotética de um diagrama de fases contendo fases oleosa/orgânica, aquosa/polar e tensoativos. Neste caso o tensoativo está associado a um cotensoativo, cuja função é diminuir a tensão interfacial para valores abaixo dos limites proporcionados pelo tensoativo comum, por isso esse diagrama pode ser chamado também de pseudoternário. Os pontos em azul podem delimitar fases caracterizadas como microemulsões, mesofases hexagonais, cúbicas, lamelares ou mesmo regiões de separação de fases

\section{Nanocápsulas e nanoesferas}

As nanocápsulas (Figura 7A) são nanoestruturas compostas de um interior ('core') oleoso rodeado por uma monocamada polimérica, sendo muito úteis na encapsulação de fármacos hidrofóbicos ou ativos como filtros de proteção solar. ${ }^{66}$ As nanocápsulas podem ser comparadas a nanosistemas vesiculares, uma vez que o fármaco pode ser confinado em uma cavidade que consiste em um núcleo líquido interno delimitado por uma membrana polimérica. Elas podem ser definidas como sistemas core-shell de modo mais fidedigno, os quais exibem uma estrutura típica de núcleo-invólucro, na qual o fármaco é confinado em um reservatório ou dentro de uma cavidade cercada por uma membrana ou revestimento de polímero. Esse reservatório pode ser lipofílico de acordo com o método de preparação e as matérias-primas utilizadas. Além disso, levando em conta as limitações operativas dos métodos de preparação, as nanocápsulas também podem transportar a substância ativa na membrana polimérica. ${ }^{67}$

Já as nanoesferas (Figura 7B) são nanoestruturas sólidas formadas por uma densa rede polimérica (matriz) sem núcleo líquido e por isso podem levar a liberação retardada de fármacos presos no interior da malha polimérica e também ter um efeito burst inicial das moléculas de fármacos adsorvidas na superfície. ${ }^{66}$ As nanoesferas são consideradas sistemas matriciais, enquanto as nanocápsulas, sistemas de reservatórios. ${ }^{68}$

Alguns dos métodos clássicos para a preparação destes NC são: nanoprecipitação, dupla emulsificação, revestimento com polímero, entre outros que são descritos por Mora-Huertas et al. ${ }^{67}$

\section{Nanopartículas lipídicas sólidas e Carreador lipídico nanoestruturado}

Nanopartículas lipídicas são classificadas em dois tipos: nanopartículas lipídicas sólidas (Figura 8A), consideradas uma primeira geração e carreadores lipídicos nanoestruturados (Figura 8B) de segunda geração. Esses NC combinam vantagens comuns a outros sistemas, tais como lipossomas e nanopartículas poliméricas, incluindo a possibilidade de carrear fármacos de diferentes características em seu interior e, semelhante aos lipossomas e nanoemulsões, apresentam em sua composição excipientes lipídicos. ${ }^{69}$

As nanopartículas lipídicas sólidas são nanoesferas compostas de um núcleo lipídico sólido. Assim como as nanopartículas poliméricas, a sua matriz sólida pode proteger eficientemente os ativos farmacêuticos contra a degradação química e proporcionar modificação dos perfis de liberação do fármaco. São sólidas tanto à temperatura ambiente quanto biológica, e compostas de lipídio sólido (0.1-30\%) disperso em fase aquosa por tensoativos. ${ }^{70}$

Os carreadores lipídicos nanoestruturados são considerados uma modificação das nanopartículas lipídicas sólidas, nos quais há presença de lipídios sólidos e líquidos a temperatura ambiente. ${ }^{72} \mathrm{~A}$ incorporação de um lipídio líquido à matriz sólida desses NC aumenta o número de imperfeições na matriz sólida interna, facilitando assim a incorporação de uma maior quantidade de fármaco e preservando a estabilidade física do NC. Esses NC podem ser produzidos em larga escala por homogeneização a alta pressão. ${ }^{72}$

\section{Nanopartículas metálicas}

Nanopartículas metálicas podem ser elaboradas a partir de diferentes materiais. Nanopartículas de ouro são uma suspensão (ou coloide) de partículas de ouro de tamanho nanométrico. Como
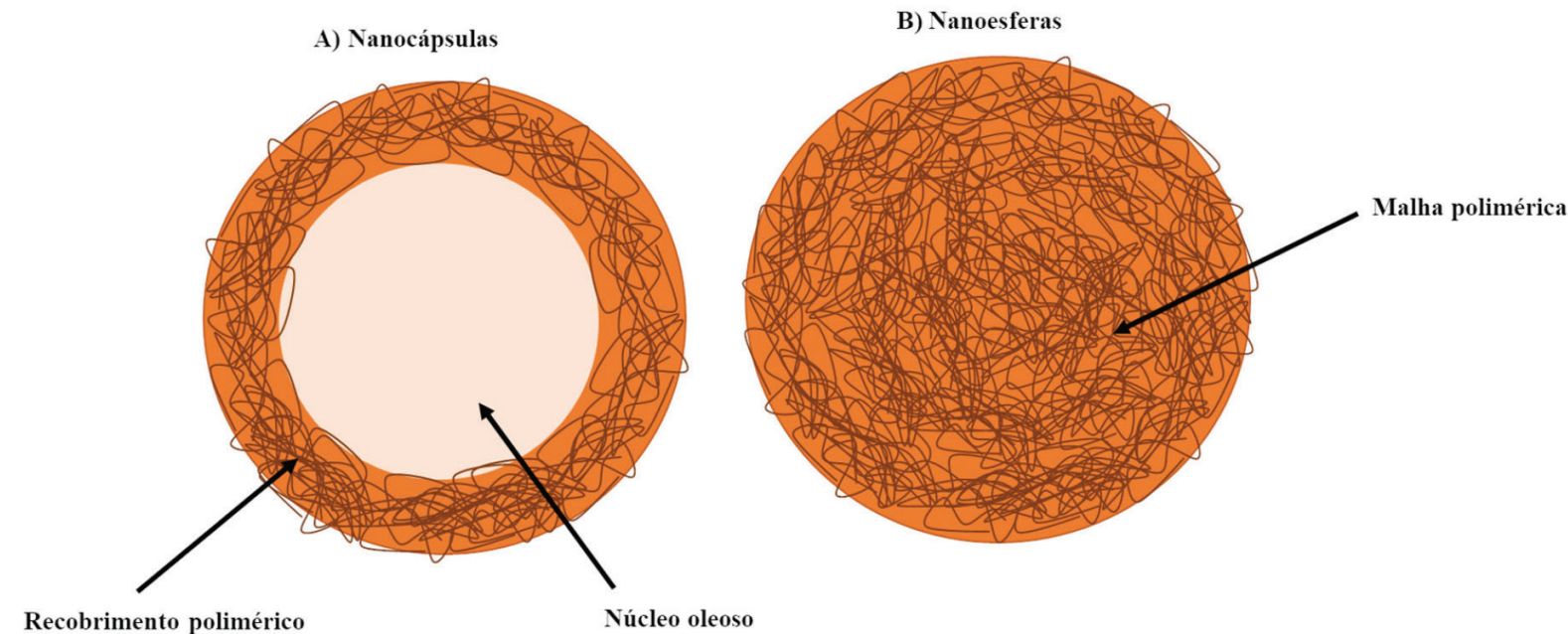

Figura 7. Representação de nanocápsulas (A) com uma camada polimérica e core oleoso onde podem estar dispersos fármacos e nanoesferas (B) com a formação de um emaranhado de polímero que forma uma malha que pode aprisionar moléculas de fármacos 

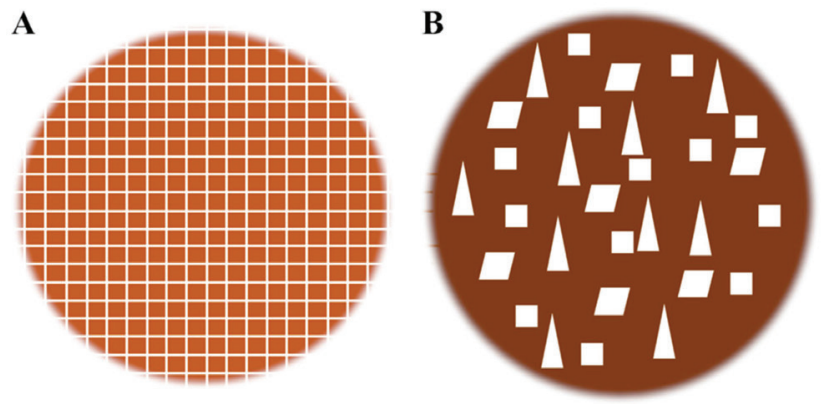

Figura 8. Representação nanopartículas lipídicas sólidas (A) com destaque para o núcleo lipídico sólido bem organizado, cristalino e carreadores lipídicos nanoestruturados (B) com núcleo lipídico desorganizado devido à presença de lipídios sólidos e líquidos à temperatura ambiente; lipídio líquido pode estar disperso formando pequenas áreas de segregação, como representado pelos quadrados e triângulos brancos baseado em conceito descrito por Müller et al. ${ }^{71}$

mencionado, anteriormente, seu uso remonta aos tempos romanos como no cálice de Licurgo. Essas suspensões coloidais foram estudas por Michael Faraday na década de 1850, quando ele observou que elas têm propriedades que diferem do ouro a granel, apresentando cor vermelha (para partículas menores que $100 \mathrm{~nm}$ ) ou uma cor amarelada suja (para partículas maiores). ${ }^{73}$ Nanopartículas de prata são amplamente usadas como agentes antimicrobianos. ${ }^{74}$ Nanopartículas de óxido de ferro são aplicados para bioimagem, biossensibilização e terapia fototérmica. ${ }^{75}$ Nanopartículas de óxido de titânio e óxido de zinco são comumente usadas em produtos como formulações contendo filtro solar. ${ }^{76}$

Nanocarreadores e modulação das propriedades físico-químicas e farmacocinéticas de fármacos

É importante compreender como os NC podem atuar levando a uma maior eficácia e segurança terapêutica. O emprego de nanocarreadores para veiculação e liberação de fármacos frequentemente busca a modulação de parâmetros farmacocinéticos, como aumento da biodisponibilidade e meia-vida, e especificidade na ação farmacológica, levando moléculas a sítio específicos do corpo, como tumores. Além disso, os nanomateriais podem combinar múltiplos métodos de direcionamento, detecção, diagnóstico e funções terapêuticas. Por exemplo, um nanomaterial pode ser projetado para se difundir do sangue até o interstício tumoral, reconhecer e penetrar em uma célula tumoral, sinalizar sua localização, escapar de um endossomo, translocar-se para o núcleo e liberar um fármaco insolúvel e citotóxico. No entanto, dependendo da finalidade determinada, algumas nanoestruturas são mais vantajosas em relação a outras.

Vale ressaltar que nanocarreadores apresentam reatividade, podendo adsorver biomoléculas do meio biológico, como proteínas e lipídios, e originando o que se conhece como "corona". ${ }^{77}$ A presença e composição da corona influenciam grandemente a distribuição e interação da nanoestrutura com células, e essas propriedades podem sem exploradas para melhorar a entrega e distribuição de fármacos. ${ }^{13,78}$ Por outro lado, com essas vantagens vêm também uma potencial toxicidade. Sabe-se que nanoestruturas podem ativar o sistema imunológico do hospedeiro, causando reações imunológicas via, por exemplo, ativação do complemento e produção de anticorpos (como os anticorpos anti-polietilenoglicol). ${ }^{79}$ Uma preocupação atual é a baixa disponibilidade de métodos in vitro humanizados bem estabelecidos, validados e de uso pré-clínico corriqueiro para avaliação de imunotoxicidade e de documentos regulatórios destinados a esse tópico. ${ }^{79}$
Nesta seção, algumas das vantagens dos NC serão discutidas com destaque para o aumento da solubilidade de fármacos, promoção da absorção, proteção contra degradação, superação de desafios relativos à aplicação terapêutica de proteínas e transposição de barreiras biológicas.

\section{Aumento da solubilidade aparente de fármacos}

A absorção de fármacos através de barreiras biológicas depende de duas propriedades: permeabilidade e solubilidade. A permeabilidade determina sua capacidade de atravessar barreiras biológicas e depende grandemente do peso molecular e $\log \mathrm{P}$ da molécula. Mas a permeabilidade adequada não assegura a absorção; sabe-se que o fármaco deve estar dissolvido em fluidos biológicos do sítio de absorção. O cetoconazol, uma base fraca, é um dos exemplos clássicos de redução da absorção oral associada ao aumento do $\mathrm{pH}$ estomacal. Quanto maior sua taxa de dissolução, mais rápida é a absorção. Para via oral, por exemplo, de acordo com sua solubilidade (mais precisamente, capacidade de dissolução) e permeabilidade, os fármacos podem ser diferenciados em 4 classes biofarmacêuticas, ${ }^{80}$ sendo a classe I representada por fármacos altamente solúveis e permeáveis, classe II por aqueles permeáveis mas que apresentam baixa solubilidade, classe III pelos de baixa permeabilidade e alta solubilidade e os de classe IV, aqueles pouco solúveis e pouco permeáveis. ${ }^{81}$

Observa-se, portanto, que o desenvolvimento de NC para fármacos classe IV é de grande interesse e o seu desenvolvimento bem-sucedido depende da composição do NC. As formas de dosagem oral ideais, por exemplo, devem produzir uma biodisponibilidade razoavelmente alta, como é o caso do Sandimmun Neoral ${ }^{\circledR}$ que é uma nanoformulação baseada em microemulsão que aumenta a solubilidade e a biodisponibilidade do peptídeo cíclico ciclosporina A, um peptídeo hidrofóbico usado como imunossupressor em transplantes e que já se encontra disponível na clínica. ${ }^{82}$

\section{Proteção contra degradação}

A encapsulação de fármacos em nanocarreadores pode proteger fármacos de degradação físico-química e enzimática, seja ela decorrente de sua exposição a condições ambientais (como luz UV) ${ }^{83}$ ou biológicas (como $\mathrm{pH}$ e presença de enzimas). ${ }^{82} \mathrm{Em}$ termos sistêmicos, é esperado que maiores quantidades de fármaco estejam disponíveis para o efeito. Além disso, menores doses de fármaco podem ser utilizadas, potencialmente reduzindo a incidência de efeitos adversos.

\section{Nanoencapsulação de biofármacos}

Biofármacos ou medicamentos biológicos, diferentes de fármacos sintéticos, não são produzidos por meio da química orgânica, mas por métodos de biologia molecular e processos biotecnológicos. ${ }^{84}$ Estes medicamentos incluem anticorpos monoclonais, fragmentos de anticorpos, peptídeos, fatores de crescimento, proteínas, oligonucleotídeos e ácidos nucleicos para terapia gênica, bem como vacinas. A Tabela 3 descreve alguns gargalos farmacológicos e físico-químicos comuns a biofármacos e como eles podem ser driblados por meio de NC.

\section{Nanocarreadores e transporte através de barreira biológicas}

Os mecanismos de transporte de fármacos incluem a passagem dentro de compartimentos definidos (por exemplo, vascular, citoplasma, estroma etc.) e entre diferentes compartimentos, em processos conduzidos por elementos de separação chamados coletivamente de "barreiras biológicas", as quais podem ser definidas como superfícies biológicas definidas tais como epitélios, endotélios, células, membranas nucleares, endossomais, etc. ${ }^{89}$ 
Tabela 3. Vantagens da nanoencapsulação de medicamentos biológicos

\begin{tabular}{|c|c|}
\hline Gargarlos & $\begin{array}{l}\text { Vantagem dos nanomedicamentos } \\
\text { biológicos }\end{array}$ \\
\hline $\begin{array}{l}\text { Peptídeos e proteínas podem } \\
\text { ser imunogênicos }\end{array}$ & $\begin{array}{l}\text { Quando encapsuladas em matrizes poli- } \\
\text { méricas ou no interior de vesículas, essas } \\
\text { moléculas não são imediatamente expostas } \\
\text { à via sistêmica, podendo levar a menor res- } \\
\text { posta imunológica. Em adição, a peguila- } \\
\text { ção do NC, por exemplo, é um recurso que } \\
\text { permite driblar a opsonização, diminuindo } \\
\text { a chance de imunogenicidade. }{ }^{85}\end{array}$ \\
\hline
\end{tabular}

\begin{tabular}{cl}
\hline $\begin{array}{c}\text { Biofármacos como proteínas } \\
\text { podem ser rapidamente } \\
\text { degradados por proteases e } \\
\text { eliminados rapidamente da } \\
\text { corrente sanguínea }\end{array}$ & $\begin{array}{c}\text { Uma vez que a macromolécula esteja } \\
\text { encapsulada durante distribuição no corpo } \\
\text { ou adentre a célula dentro de um nanocar- } \\
\text { reador em terapia intracelular, ela pode es- } \\
\text { capar de sofrer ação de enzimas sistêmicas } \\
\text { ou proteases plasmáticas e lisossomais. }{ }^{86}\end{array}$ \\
\hline $\begin{array}{c}\text { Doses repetidas dos } \\
\text { biofármacos são necessárias } \\
\text { para manter os níveis } \\
\text { terapêuticos }\end{array}$ & $\begin{array}{l}\text { Uma vez que a degradação e a opsonização } \\
\text { podem ser atenuadas com o uso de NC, } \\
\text { a meia-vida do fármaco pode aumentar } \\
\text { significativamente. }\end{array}$ \\
\hline
\end{tabular}

Modificando o método de encapsulação (com mínima agitação e sem emprego de altas temperaturas, por exemplo) e depen-

Peptídeos e proteínas terapêuticas também tendem a sofrer agregação, adsorção e desnaturação dendo da nanoestrutura usada (vesículas, proteínas peguiladas), pode haver uma diminuição da exposição dos biofárma$\cos$ a fatores que levem à instabilidade das biomoléculas, como temperatura e mudanças de $\mathrm{pH}$. Nos casos em que são usadas enzimas, a atividade terapêutica pode inclusive aumentar. ${ }^{87}$

RNAs de pequena interferência (do inglês small interfering RNA/ siRNA) precisam ser incorporados no complexo silenciador induzido por RNA que medeia uma sequência específica de ligação e clivagem de RNAm. Desse modo, a penetração intracelular é fundamental e pode ser alcançada com uso de nanocarreadores adequados e que evitem a degradação por nucleases. Carreadores lipídicos carregados positivamente têm sido extensivamente usados para carrear estas moléculas através de interações eletrostáticas com os grupos fosfato carregados negativamente da molécula de siRNA. ${ }^{88}$

Essa jornada entre compartimentos também inclue os mecanismos de evasão dos monócitos e macrófagos ativados do sistema reticuloendotelial, que levam ao clearance e escape de degradação enzimática.

\section{Nanocarreadores e pele}

A pele pode ser usada como via de administração para liberação de fármacos no próprio tecido ou através dele. No primeiro caso, o objetivo é o efeito local e a minimização da absorção sistêmica dos fármacos. Ao contrário, quando a absorção e efeito sistêmicos são desejados, nos referimos à administração transdérmica. É comum uma confusão entre os termos tópico e transdérmico; assim, iremos nos referir a liberação tópica quando o efeito farmacológico apenas na pele é almejado, e transdérmica, quando o fármaco deverá ser sistemicamente absorvido e distribuído para atingir seu alvo e exercer seu efeito farmacológico. Diferentes NC têm sido estudados para essas finalidades, como nano e microemulsões, ${ }^{53,54}$ nanopartículas lipídicas ${ }^{90}$ e lipossomas.
O tratamento de feridas é um exemplo do uso de NC tópico, pois nessa situação a pele está rompida e há a necessidade da localização do ativo no local, bem como sua proteção de possível degradação em razão da presença de enzimas que agem nas diversas fases de cicatrização. Além disso, a espessura total da pele é parcialmente comprometida e há outro desafio relacionado à abundância de células inflamatórias e clearance de NC, sendo que modificações de superfície de NC podem permitir a evasão seletiva do clearance fagocitário por macrófagos. ${ }^{91}$

A administração de fármacos por via transdérmica tem importância crescente, especialmente para aqueles sujeitos à extensa eliminação pré-sistêmica, o que reduz sua biodisponibilidade. Além do efeito sistêmico, os nanomedicamentos transdérmicos podem exercer seu papel nos tecidos adjacentes à sua aplicação (terapia transdérmica local), como a administração na mama para atingir tumores mamários, evitando assim reações adversas sistêmicas ${ }^{92-94}$ ou aplicação em áreas de inflamação para diminuir inchaço e dor.

Em pele íntegra, o estrato córneo (EC), camada mais externa da epiderme, é considerado a principal barreira a ser transposta pelos NC. O EC apresenta cerca de 18 a 21 camadas de células sendo composto de queratinócitos mortos chamados corneócitos, os quais são mantidos juntos por uma rede de proteínas como a queratina e revestidos por uma camada de lipídeos (principalmente ceramidas). $\mathrm{O}$ EC e as junções apertadas no estrato granuloso criam uma barreira impermeável à maioria das moléculas de fármaco hidrofílicas e de peso molecular superior à $500 \mathrm{Da} .{ }^{95}$ Quando os fármacos atravessam o EC e atingem a epiderme viável, têm acesso a queratinócitos viáveis e células imunologicamente ativas que podem permitir a penetração de NC e drenagem por linfonodos. ${ }^{96}$

Idealmente, os NC devem permitir o transporte de fármacos encapsulados ou adsorvidos na pele sem a necessidade de danificar a função de barreira natural, se deformando, ou utilizando promotores de permeação cutânea. Assim, podem facilitar o fornecimento de agentes ativos por meio das estruturas da pele, interagir com os lipídios para mediar o transporte e permitir a criação de depósitos de fármacos na pele para uma liberação sustentada ou induzida por estímulos. ${ }^{92}$ As três rotas potenciais de entrada de fármacos através da pele para o tecido subepidérmico são: através dos folículos capilares com suas glândulas sebáceas associadas, através dos ductos sudoríparos ou através do estrato córneo contínuo intracelularmente através de corneócitos, intercelularmente ao redor de corneócitos e entre esses apêndices. ${ }^{97}$

Para essa finalidade a literatura tem relatado o uso de lipossomas, vesículas deformáveis (transfersomas), vesículas contendo promotores de permeação (niossomas, etossomas, transetossomas), nanopartículas lipídicas ou poliméricas, micro e nanoemulsões e dendrímeros. ${ }^{98,99}$

\section{Nanocarreadores e barreira intestinal: via oral}

Nanocarreadores podem ser empregados por via oral para diversas finalidades, sendo o aumento da biodisponibilidade uma das principais. ${ }^{100} \mathrm{~A}$ absorção de fármacos no trato gastrointestinal (TGI) ocorre majoritariamente no intestino e há três mecanismos principais pelos quais isso acontece após a molécula atravessar a camada de muco. ${ }^{65}$ O primeiro deles é a absorção passiva, em que a molécula atravessa as células da membrana apical para a basolateral e entra na circulação sanguínea; devido à natureza lipídica da membrana plasmática, esse processo permite a penetração de moléculas lipofílicas mas dificulta o transporte de compostos hidrofílicos, além de não ser seletivo. Outro meio passivo utiliza as tight junctions ou junções aderentes, zona em que uma célula se une a outra e permite a passagem de moléculas; esse, por sua vez, tem melhor transporte de moléculas hidrofílicas e também não é seletivo. O último utiliza transportadores presentes 
na membrana apical que aceleram o processo de absorção e pode ser tanto passivo, quanto ativo; tem melhor seletividade e é responsável pela maior parte da absorção dos nutrientes. ${ }^{65}$

Fármacos muito insolúveis não utilizam nenhum dos transportes citados eficientemente quando administrados na forma livre. Pooja et al. ${ }^{101}$ explora essa problemática ao incorporar o paclitaxel em um nanocarreador lipídico sólido para administração oral e conjugando em sua superfície lecitina derivada de gérmen de trigo. Foi demonstrado que essa abordagem levou ao aumento da biodisponibilidade do paclitaxel em ratos, fato que o autor atribui a interação com células $\mathrm{M}$ das placas de Peyer presentes no intestino que podem englobar os nanocarreadores e transportá-los diretamente ao sistema linfático. ${ }^{102}$ Foi demonstrado que houve seu acúmulo em diversos tecidos, mas principalmente no pulmão, mostrando seu potencial em quadros de câncer nesse local.

Outra estratégia interessante que permite sobrepujar as barreiras intestinais é a utilização de moléculas zwiteriônicas biocompatíveis na superfície de nanocarreadores lipídicos sólidos. Shan et al. ${ }^{103}$ demonstraram que é possível melhorar a biodisponibilidade oral de macromoléculas, como a insulina, ao utilizar dilauroilfosfatidilcolina na superfície de seu nanocarreador; foi demonstrado aumento na difusão pela camada de muco e melhora na afinidade com enterócitos através de sua ligação com transportadores PEPT1 presentes na membrana apical que permitiu a internalização do sistema sem danificar a integridade das células.

\section{Nanocarreadores e barreira placentária: tratamento fetal}

A placenta é o órgão vascular que une o feto à parede do útero materno com funções endócrina, parácrina e autócrina, metabolismo, proteção e transporte de substâncias e é constituída por tecidos de origem embrionária que formam a chamada barreira placentária. ${ }^{104}$

A entrega de moléculas menos invasiva e mais específica pode ser feita através de NCs, seja diminuindo a exposição fetal a um determinado fármaco, quanto de forma a aumentar a retenção deste na placenta. Ainda, com o avanço do diagnóstico fetal in uterus, a terapia fetal por meio da administração de fármacos no organismo materno começou a ser uma forma viável de modular funções da placenta e minimizar ou prevenir riscos à saúde do feto, disponibilizando fármacos para tratamento de condições fetais. ${ }^{105,106}$

Um trabalho desenvolvido por Abd Ellah et al. ${ }^{107}$ demonstrou em modelos in vivo o potencial de nanopartículas poliméricas de promover a liberação na placenta do gene do fator de crescimento IGF-1, responsável pelo desenvolvimento placentário e fetal, de forma a tratar a restrição do crescimento intrauterino, uma condição para a qual ainda não há tratamento a não ser o parto prematuro, o qual pode levar a diversas complicações. As nanopartículas estudadas foram capazes de se localizar na placenta e induzir a expressão do gene aumentando assim, o peso do feto.

Em se tratando da terapia fetal propriamente dita, um estudo desenvolvido por Bajoria e colaboradores, em 1997 demonstraram o potencial terapêutico não-invasivo de lipossomas aniônicos para aumentar a transferência placentária de tiroxina minimizando a exposição materna à substância para o tratamento de hipotireoidismo congênito fetal, em modelo de placenta humana retirada após o período expulsivo (ex-vivo). ${ }^{108}$

\section{Nanocarreadores e barreira hematoencefálica}

Uma das maiores dificuldades para o tratamento das enfermidades do SNC é ultrapassar a BHE. Composta por células endoteliais com diversos tipos de ligações e mecanismos capazes de impedir a passagem de substâncias para o cérebro, a BHE possui diversas moléculas de adesão juncional, claudinas e ocludinas, além de proteínas citoplasmáticas que impedem seletivamente a passagem de certas substâncias. ${ }^{109}$

Para vencer esses mecanismos, os fármacos ou NC precisam apresentar certa lipofilicidade, tamanhos menores que $500 \mathrm{Da}$, serem capazes de inibir a glicoproteína-P e a capacidade de atravessar passivamente esta barreira, como por exemplo, ao se ancorar à apolipoproteínas, as quais possuem receptores específicos na BHE. Outras abordagens vêm sendo estudadas, como a conjugação das nanopartículas com anticorpos para receptores de glicose como o GLUT1, presente nas células endoteliais da BHE, ou ainda receptores de insulina. ${ }^{110}$

De modo geral, alguns mecanismos ou propriedades físico-químicas das moléculas ou ainda NC vêm sendo utilizados para ultrapassar a BHE, como a passagem pelas junções oclusivas de moléculas hidrossolúveis, através da via de difusão hidrofílica paracelular; pela difusão passiva de moléculas lipossolúveis pelas células endoteliais; por vias de endocitose ou transcitose; ou ainda pela maquinaria de transporte de peptídeos ou pequenas moléculas. Muitos NC utilizam alterações superficiais como aptâmeros, peptídeos ou anticorpos para uma ação mais alvo-dirigida, enquanto outros optam por a utilização de PEG ou outros polímeros para uma direção mais passiva do alvo. Além disso, podemos considerar NC que possuem moléculas incorporadas com características que promoverão a passagem pela BHE, como moléculas hidrofílicas ou hidrofóbicas, lipídios catiônicos e moléculas lipofílicas. ${ }^{111}$ A utilização de polímeros naturais, como a quitosana e alginato, ou aminoácidos, como a polilisina, poli ácido aspártico, ou proteínas como gelatina e albumina, parecem facilitar a passagem pela BHE. ${ }^{112}$

Nanocarreadores e tumores: efeito de permeação e retenção

A liberação de fármacos no ambiente tumoral pode envolver o EPR, e a penetração intracelular de nanoestruturas. No caso do EPR temos um processo passivo como já explicado anteriormente. Já mediante o uptake celular, promove-se a liberação de moléculas (i.e., genes, fármacos e contrastes) no citoplasma, núcleo ou outros sítios intracelulares específicos, sendo um pré-requisito que os NCs sejam transportados através da membrana plasmática de maneira eficiente. ${ }^{113}$ É possível ainda a utilização de marcadores expressos em tumores para aumentar a seletividade do nanocarreador e melhorar sua internalização, no que conhecemos como "direcionamento ativo". Assim, a superfície do nanocarreador pode ser modificada com ligantes, anticorpos e substratos desses marcadores para conferir direcionamento ativo. ${ }^{77}$

Quando os NCs alcançam a membrana exterior de uma célula, eles podem interagir com componentes da membrana plasmática ou matriz extracelular e entrar na célula principalmente através de endocitose. ${ }^{24}$ No entanto, é a biocorona, e não o nanocarreador tal qual produzido, que interage com as células. Ela altera o tamanho e composição superficial de um nanomaterial, conferindo-lhe uma identidade biológica distinta da sua identidade sintética. ${ }^{114}$

Para NCs que não podem atravessar diretamente a membrana plasmática, sua penetração celular pode ser mediada por endocitose fagocítica e pinocítica. ${ }^{25} \mathrm{~A}$ penetração na célula ocorre principalmente por endocitose e leva ao envolvimento dos $\mathrm{NC}$ em invaginações de membrana, seguido de seu brotamento para formar vesículas endocíticas, que são então transportadas para compartimentos especializados no ambiente intracelular. ${ }^{24}$

Os mecanismos para uptake dependem de tamanho, superfície e forma como ilustrado na Figura 9. O processo pode ser explicado por diferentes mecanismos como a macropinocitose (uma via dependente de actina com grandes vacúolos). A endocitose mediada por clatrina também pode ser desencadeada, levando ao recrutamento de receptores de superfície celular para ligação aos NC e à formação de poços 
recobertos com clatrina que englobam os NC. A vesícula revestida "brota" na célula e, depois de espalhar a camada, a vesícula se funde com endossomos que se movem da membrana plasmática para os lisossomos. Também é relatada a endocitose mediada por cavéolas, na qual há a internalização do ligante extracelular e biomoléculas através de invaginações em forma de balão (cavéolas) que são formadas por proteína de ligação ao colesterol (caveolina); ainda pode-se citar a endocitose não mediada por clatrina e ou por caveolina. ${ }^{115}$

Aqui é importante ainda destacar que o sucesso dos nanofármacos depende não só da penetração na célula, mas do escape endossomal bem-sucedido, de modo que esses atinjam o citosol. Na maioria das vezes, os NC não podem atravessar a membrana endossômica diretamente e estratégias podem ser usadas para induzir mecanismos de escape, como a fusão entre o NC e membrana endossômica. As estratégias para o escape endossomal de $\mathrm{NC}$ incluem o uso de peptídeos de transdução (do inglês cell-penetrating peptide/CPPs) e alterações na composição e superfície do $\mathrm{NC}$ a fim de promover a fusão com a membrana endossômica. ${ }^{25}$

\section{As novas gerações de nanocarreadores}

Atualmente, os NC não trazem o tamanho como atrativo apenas, mas diversas características que os classificam como 'nanocarreadores inteligentes' (do inglês: smart nanocarriers) ou composição diferenciada, sendo então chamados de nanocarreadores decorados ou funcionalizados (do inglês: decorated nanocarriers). Os nanocarreadores inteligentes podem ser responsivos a fatores externos como $\mathrm{pH},{ }^{116}$ temperatura, ${ }^{117}$ potencial redox ${ }^{118}$ e campo magnético. ${ }^{118} \mathrm{Um}$ exemplo de nanocarreador inteligente é o ThermoDox ${ }^{\circledR}$, um nanomedicamento que já se encontra em estudos clínicos para tratamento de diferentes tipos de câncer e que não depende do efeito EPR. Sob condição de hipertermia local aplicada antes ou logo após a administração ( $\mathrm{T} \geq 40^{\circ} \mathrm{C}$ ) através de ablação de alta frequência, a doxorrubicina é liberada dentro de segundos das vesículas e difunde-se rapidamente no local. ${ }^{119}$ In vivo, o calor é geralmente aplicado usando-se sacos de água com temperatura controlada, osciladores de radiofrequência ou aplicadores de microondas. Nos últimos anos, o foco tem sido o desempenho rápido e quantitativo da liberação de fámacos. ${ }^{118}$

Já as nanoestruturas decoradas podem conter moléculas que facilitariam a precisão de atuação dos nanocarreadores bem como a penetração intracelular através da sua ligação a receptores super-expressos nas células. Já estão sendo estudados: folato, ${ }^{120}$ transferrina, ${ }^{121}$ glicanos, ${ }^{122}$ ácido hialurônico, ${ }^{123}$ peptídeos. ${ }^{124}$

Além das modificações citadas acima, há nanocarreadores estudados dentro do campo de provas de conceito como polimerossomas susceptíveis a estímulos químicos (quimiotaxia) ${ }^{125}$ ou abordagens do desenvolvimento de nanobiorreatores, que seriam vesículas contendo enzimas e cujas reações ocorreriam no interior delas com penetração dos substratos. ${ }^{85}$

\section{Regulamentação para nanomedicamentos}

Como já mencionado antes, até 2014 havia uma certa falta de padronização das agências regulatórias internacionais no que diz respeito às definições de nanotecnologia aceitas para a aprovação de nanomedicamentos. É interessante observar que antes do estabelecimento dessa definição, já havia nanomedicamentos aprovados, como o caso da Doxil (doxorrubicina lipossomal) que é considerado o primeiro medicamento com base em nanotecnologia aprovado em 1995. Em 2017, um draft de um guia da FDA, o qual ainda não está em fase de implementação, intitulado "Drug Products, Including Biological Products, that Contain Nanomaterials", ${ }^{3}$ descreve que a regulamentação desses produtos deve seguir as normas já vigentes para os medicamentos que não envolvem nanotecnologia na produção e devem, portanto, ser classificados nas categorias já existentes: novos medicamentos, biofármacos e genéricos. A FDA também publicou alguns guias direcionados a determinados nanomedicamentos, como os lipossomas em 2018, o qual é intitulado “Liposome Drug Products:

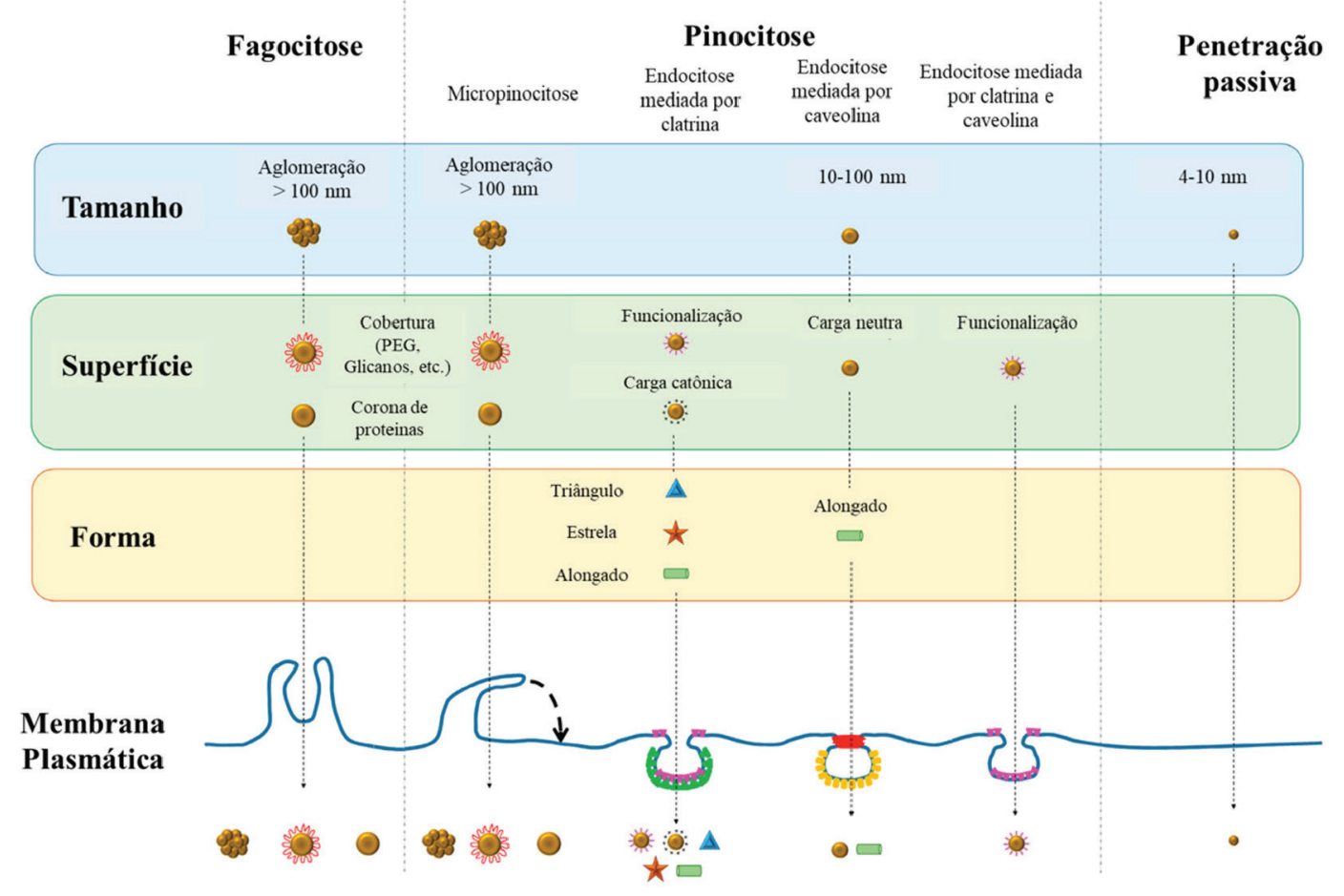

Figura 9. Representação das possíveis vias pelas quais os nanocarreadores podem penetrar na célula. Adaptado (por meio de tradução) de: https://www. mdpi.com/1422-0067/19/5/1305, Panzarini et al., ${ }^{115}$ um artigo Open Access distribuído pelos termos da Creative Commons Attribution License que permite uso, distribuição e reprodução 
Chemistry, Manufacturing, and Controls; Human Pharmacokinetics and Bioavailability; and Labeling Documentation", ${ }^{126}$ o qual discute que tipos de informação devem ser consideradas para registro de nanomedicamentos do tipo lipossomas.

A agência europeia EMA (European Medicines Agency) tem publicados artigos com reflexões sobre alguns assuntos como nanocarreadores com revestimento de superfície, lipossomas intravenosos, micelas poliméricas e nanopartículas de ferro. ${ }^{127-130}$ Esses documentos são aplicados a novos nanomedicamentos e nanossimilares, e visam orientar os fabricantes nas solicitações de aprovação. Essa agência demonstra preocupações inclusive em relação aos produtos já aprovados e em julho de 2019 decretou que todos os detentores de autorização de medicamentos baseados em lipossomas na União Europeia deveriam enviar até setembro deste mesmo ano uma variação para alterar os nomes desses medicamentos e deixar claro a distinção entre as formulações lipossomais e convencionais. O objetivo dessa determinação é evitar erros de prescrição, uma vez que como já amplamente discutido neste artigo, os nanomedicamentos apresentam diferenças nas propriedades de liberação e/ou biodistribuição. ${ }^{131}$

Apesar dessas agências demonstrarem rigidez na aprovação de produtos, alguns autores contestam a extrapolação da legislação para os critérios usados com os medicamentos que não apresentam abordagens de nanotecnologia. Um exemplo é o caso do registro dos genéricos pela FDA como criticado por Emily et al.,${ }^{14}$ que enfatizaram que nanomedicamentos podem não ser adequadamente caracterizados quanto à uniformidade, podem apresentar diferenças em razão das técnicas de fabricação e, consequentemente, diferentes propriedades farmacocinéticas e farmacodinâmicas. Em consonância a isso, em um estudo que visava estabelecer uma comparação morfológica e imunológica entre Doxil ${ }^{\circledR}$, Caelyx $^{\circledR}{ }^{\circledR}$ DOXOrubicin e SinaDoxosome, foram relatadas diferenças morfológicas não apenas entre Doxil ${ }^{\circledR} \mathrm{e}$ os similares, mas também entre Doxil ${ }^{\circledR}$ e Caelyx ${ }^{\circledR}$, considerados por agências regulatórias como idênticos. ${ }^{132}$

No Brasil, os nanomedicamentos têm sido registrados também dentro das categorias já existentes e alguns foram até sido registrados como similares como é o caso do Ambisome ${ }^{\circledR}$ (anfotericina B lipossomal) e Daunoxome ${ }^{\circledR}$ (Citrato de Daunorrubicina). É importante ressaltar que por meio do Ministério da Ciência, Tecnologia, Inovações e Comunicações (MCTIC) mesmo sem vínculo direto com a ANVISA, o Brasil foi signatário da NANoREG, composta por 85 membros da União Européia, Coreia e Brasil. Essa iniciativa internacional teve por objetivo o desenvolvimento de métodos confiáveis e reprodutíveis para a avaliação dos efeitos e segurança de nanomateriais na saúde e ambiente dentro do contexto regulatório. Embora a iniciativa tenha sido finalizada em 2017, ela apresenta-se atualmente como um repositório on line de procedimentos e normas de segurança de materiais nanotecnológicos, importantes para estabelecer padrões de qualidade para esses produtos.

\section{CONCLUSÕES}

Já passada a maioridade do século 21 e diante da revolução tecnológica que temos vivenciado nas mais diversas áreas do conhecimento com a recente revolução da indústria 4.0, as promessas da nanotecnologia aplicada ao campo médico e farmacêutico continuam atraentes e desafiadoras, levando pesquisadores de diferentes campos do conhecimento a desenvolver nanocarreadores visando a administração de fármacos. A principal vantagem relatada é a associação entre eficácia farmacológica, aumento da especificidade e redução de efeitos adversos atribuída ao nanomedicamento, o que pode ser atingido por meio da encapsulação de moléculas hidrofóbicas ou sensíveis à degradação como biofármacos, e levaria a uma melhor biodisponibilidade delas, por permitir a passagem pelas barreiras biológicas como pele, barreira hematoencefálica e intestinal, bem como sua localização em tecidos tumorais e sítios inflamatórios.

Além disso, desde as primeiras descrições científicas da nanotecnologia na década de 70, a tecnologia de produção dos nanomedicamentos têm evoluído concomitantemente com a evolução da indústria química, especialmente de polímeros, e grupos de pesquisa do mundo todo estão constantemente relatando "nanocarreadores inteligentes", capazes de liberar fármacos sob estímulos externos de mudanças de temperatura, por exemplo. Outra abordagem é a modificação das superfícies das nanoestruturas, permitindo a interação com alvos nas células e posterior internalização. No entanto, mesmo com tantas pesquisas envolvendo a produção de nanocarreadores, há inúmeras perguntas a serem respondidas no campo da farmacologia (que poderia ser aqui chamado de nanofarmacologia) já que os nanomedicamentos podem modular propriedades farmacodinâmicas (ex. resistência à fármacos) ou farmacocinéticas (ex. aumento da meia-vida), levando à necessidade de quebrar paradigmas da farmacologia clássica. Essas lacunas se refletem na pouca quantidade de produtos aprovados para uso quando comparados com a imensa quantidade de artigos científicos publicados. Uma séria de aspectos referentes à aplicação da nanotecnologia no desenvolvimento, compreensão de ação e aprovação de medicamentos ainda parece estar dentro de uma "Caixa de Pandora", e as próprias agências regulatórias como FDA, EMA e ANVISA demonstram preocupações com a relativa falta de padronização do controle de qualidade para os nanomedicamentos. Iniciativas como a NANoREG e o repositório resultante da iniciativa têm papel muito importante na identificação e adoção de parâmetros de qualidade, a fim de garantir que os nanomedicamentos estejam em conformidade com padrões internacionais.

\section{AGRADECIMENTOS}

Os autores agradecem o suporte financeiro (FAPESP \#2018/13877-1, INCT Nanofarma: FAPESP \#2014/50928-2 e CNPq \# 465687/2014-8) e na forma de bolsas (CAPES, código de financiamento 001, e FAPESP\# 2018/14375-0 e 2017/23213-0).

\section{REFERÊNCIAS}

1. Hassan, S.; Prakash, G.; Bal, A.; Saghazadeh, S.; Shrike, Y.; Khademhosseini, A.; Bal Ozturk, A.; Saghazadeh, S.; Farhan Sohail, M.; Seo, J.; Remzi Dokmeci, M.; Zhang, Y. S.; Khademhosseini, A.; Nano Today 2017, 15, 91.

2. Feynman, R. P.; Eng. Sci. 1960, 23, 22.

3. Food and Drug Administration Drug Products, Including Biological Products, that Contain Nanomaterials - Guidance for Industry, 2017.

4. Torrice, M.; ACS Cent. Sci. 2016, 2, 434.

5. Florence, A. T.; Int. J. Pharm. 2018, 551, 1.

6. Reineke, J.; J. Control. Release 2018, 273, 180.

7. Witzigmann, D.; Hak, S.; van der Meel, R.; J. Control. Release 2018, 290,138

8. Cheng, Z.; Zaki, A. A. Al; Hui, J. Z. Z.; Muzykantov, V. R. R.; Tsourkas, A.; Science (80-. ). 2012, 338, 903.

9. Danhier, F.; J. Control. Release 2016, 244, 108.

10. Cevc, G.; Vierl, U.; J. Control. Release 2010, 141, 277.

11. von Roemeling, C.; Jiang, W.; Chan, C. K.; Weissman, I. L.; Kim, B. Y. S.; Trends Biotechnol. 2017, 35, 159.

12. Food and Drug Administration, 2014, 1.

13. Soares, S.; Sousa, J.; Pais, A.; Vitorino, C.; Front. Chem. 2018, 6, 1.

14. Emily, M.; Ioanna, N.; Scott, B.; Beat, F.; AAPS J. 2018, $20,1$.

15. Schaffazick, S. R.; Guterres, S. S.; De Lucca Freitas, L.; Pohlmann, A. R.; Freitas, L.; Pohlmann, A. R.; New Chem. 2003, 26, 726.

16. McClements, D. J.; Soft Matter 2012, 8, 1719. 
17. Li, H.; Williams, G. R.; Wu, J.; Lv, Y.; Sun, X.; Wu, H.; Zhu, L. M.; Int. J. Pharm. 2017, 517, 135.

18. Pegoraro, C.; Cecchin, D.; Madsen, J.; Warren, N.; Armes, S. P.; Macneil, S.; Lewis, A.; Battaglia, G.; Biomater. Sci. 2014, 2, 680.

19. Park, K.; J. Control. Release 2017, 267, 2.

20. Hasan, A. S.; Socha, M.; Lamprecht, A.; Ghazouani, F. El; Sapin, A.; Hoffman, M.; Maincent, P.; Ubrich, N.; Int. J. Pharm. 2007, 344, 53.

21. Maeda, H.; Tsukigawa, K.; Fang, J.; Microcirculation 2016, 23, 173.

22. Kemp, J. A.; Shim, M. S.; Heo, C. Y.; Kwon, Y. J.; Adv. Drug Deliv. Rev. 2016, 98,3

23. Aparicio-Blanco, J.; Martín-Sabroso, C.; Torres-Suárez, A. I.; Biomaterials 2016, 103, 229.

24. Behzadi, S.; Serpooshan, V.; Tao, W.; Hamaly, M. A.; Alkawareek, M. Y.; Dreaden, E. C.; Brown, D.; Alkilany, A. M.; Farokhzad, O. C.; Mahmoudi, M.; Chem. Soc. Rev. 2017, 46, 4218.

25. Li, Y.; Wang, J.; Wientjes, M. G.; Au, J. L.-S.; Adv. Drug. Deliv. Rev. 2012, 64, 29.

26. Li, S.-D.; Huang, L.; J Control Release 2010, 145, 178.

27. Wang, Y.; Hosta-Rigau, L.; Lomas, H.; Caruso, F.; Phys. Chem. Chem. Phys. 2011, 13, 4782.

28. Westmeier, D.; Stauber, R. H.; Docter, D.; Toxicol. Appl. Pharmacol. 2016, 299, 53.

29. Lammers, T.; Aime, S.; Hennink, W. E.; Storm, G.; Kiessling, F.; Acc. Chem. Res. 2011, 44, 1029.

30. Lopresti, C.; Massignani, M.; Fernyhough, C.; Blanazs, A.; Ryan, A. J.; Madsen, J.; Warren, N. J.; Armes, S. P.; Lewis, A. L.; Chirasatitsin, S.; Engler, A. J.; Battaglia, G.; ACS Nano 2011, 5, 1775.

31. Franzè, S.; Musazzi, U. M.; Minghetti, P.; Cilurzo, F.; Eur. J. Pharm. Sci. 2019, 130, 27.

32. Allen, T. M.; Cullis, P. R.; Adv. Drug Deliv. Rev. 2013, 65, 36.

33. Bangham, A. D.; Standish, M. M.; Watkins, J. C.; J. Mol. Biol. 1965, 13, 238.

34. Worch, R.; Petrášek, Z.; Schwille, P.; Weidemann, T.; J. Membr. Biol. 2017, 250, 393.

35. Olusanya, T. O. B.; Ahmad, R. R. H.; Ibegbu, D. M.; Smith, J. R.; Elkordy, A. A.; Molecules 2018, 23, 1.

36. Rattanapak, T.; Young, K.; Rades, T.; Hook, S.; J. Pharm. Pharmacol. 2012, 64, 1560.

37. Daraee, H.; Etemadi, A.; Kouhi, M.; Alimirzalu, S.; Daraee, H.; Etemadi, A.; Kouhi, M.; Alimirzalu, S.; Akbarzadeh, A.; Artif. Cells, Nanomed., Biotechnol. 2016, 44, 381.

38. Reddy, K. R.; Ann. Pharmacother. 2000, 3, 915

39. Jaafar-Maalej, C.; Diab, R.; Andrieu, V.; Elaissari, A.; Fessi, H.; JaafarMaalej, C.; Diab, R.; Andrieu, V.; Elaissari, A.; J. Liposome Res. 2010, 20, 228.

40. Discher, B. M.; Won, Y.-Y.; Ege, D. S.; Lee, J. C.-M.; Bates, F. S.; Discher, D. E.; Hammer, D. A.; Science (80-. ). 1999, 284, 1143.

41. Apolinário, A. C.; Pachioni-Vasconcelos, J. de A.; Pessoa-Jr., A.; Rangel-Yagui, C. de O.; De Almeida Pachioni-Vasconcelos, J.; Pessoa, A.; De Oliveira Rangel-Yagui, C.; Quim. Nova 2017, 40, 810.

42. Apolinário, A.; Magoń, M.; Pessoa Jr., A.; Rangel-Yagui, C.; Nanomaterials 2018, 8, 373.

43. Battaglia, G.; Ryan, A. J.; J. Phys. Chem. B 2006, 110, 10272.

44. Wang, L.; Chierico, L.; Little, D.; Patikarnmonthon, N.; Yang, Z.; Azzouz, M.; Madsen, J.; Armes, S. P.; Battaglia, G.; Angew. Chem., Int. Ed. 2012, 51, 11122 .

45. Bleul, R.; Thiermann, R.; Maskos, M.; Macromolecules 2015, 48, 7396.

46. Mai, Y.; Eisenberg, A.; Chem. Soc. Rev. 2012, 41, 5969.

47. Danielsson, I.; Lindman, B.; Colloids Surf. 1981, 3, 391.

48. Hoar, T. P.; Schulman, J. H.; Nature 1943.

49. Rosano, H. L.; Clausse, M. Microemulsion Systems, $1^{\text {st }}$ ed., Marcel Dekker: New York, 1987.
50. Pepe, D.; Mccall, M.; Zheng, H.; Lopes, L. B.; J. Pharm. Sci. 2013, 102, 1476.

51. Lopes, L. B.; Pharmaceutics 2014, 6, 52.

52. Lindman, B.; Shinoda, K.; Olsson, U.; Anderson, D.; Karlström, G.; Wennerström, H.; Colloids Surf. 1989, 38, 205.

53. Thomas, S.; Vieira, C. S.; Hass, M. A.; Lopes, L. B.; J. Pharm. Sci. 2014, 103, 2530.

54. Carvalho, V. F. M.; Migotto, A.; Giacone, D. V.; de Lemos, D. P.; Zanoni, T. B.; Maria-Engler, S. S.; Costa-Lotufo, L. V.; Lopes, L. B.; Eur. J. Pharm. Sci. 2017, 109, 131.

55. Nastiti, C. M. R. R.; Ponto, T.; Abd, E.; Grice, J. E.; Benson, H. A. E.; Roberts, M. S.; Pharmaceutics 2017, 9, 1.

56. Delmas, T.; Piraux, H.; Couffin, A. C.; Texier, I.; Vinet, F.; Poulin, P.; Cates, M. E.; Bibette, J.; Langmuir 2011, 27, 1683.

57. Carvalho, V. F. M.; Salata, G. C.; de Matos, J. K. R.; Costa-Fernandez, S.; Chorilli, M.; Steiner, A. A.; de Araujo, G. L. B.; Silveira, E. R.; Costa-Lotufo, L. V.; Lopes, L. B.; Int. J. Pharm. 2019, 567.

58. Awad, T. S.; Asker, D.; Romsted, L. S.; J. Colloid Interface Sci. 2018 , $514,83$.

59. Phelps, J.; Bentley, M. V. L. B.; Lopes, L. B.; Colloids Surf., B 2011, 87, 391.

60. Hosmer, J. M.; Steiner, A. A.; Lopes, L. B.; Pharm. Res. 2013, $30,694$. 61. Singh, S.; Phys. Rep. 2000, 324, 107.

62. Lopes, L. B.; Lopes, J. L. C.; Oliveira, D. C. R.; Thomazini, J. A.; Garcia, M. T. J.; Fantini, M. C. A.; Collett, J. H.; Bentley, M. V. L. B.; Eur. J. Pharm. Biopharm. 2006, 63, 146.

63. Depieri, L. V.; Borgheti-Cardoso, L. N.; Campos, P. M.; Otaguiri, K. K.; De Carvalho Vicentini, F. T. M.; Lopes, L. B.; Fonseca, M. J. V.; Bentley, M. V. L. B.; Eur. J. Pharm. Biopharm. 2016, 105, 50.

64. Shah, J. C.; Sadhale, Y.; Chilukuri, D. M.; Adv. Drug Deliv. Rev. 2001, $47,229$.

65. Ezrahi, S.; Aserin, A.; Garti, N.; Adv. Colloid Interface Sci. 2019, 263, 95.

66. Letchford, K.; Burt, H.; Eur. J. Pharm. Biopharm. 2007, 65, 259.

67. Mora-Huertas, C. E.; Fessi, H.; Elaissari, A.; Int. J. Pharm. 2010, 385 , 113.

68. Teixeira, M.; Alonso, M. J.; Pinto, M. M. M.; Barbosa, C. M.; Eur. J. Pharm. Biopharm. 2005, 59, 491.

69. Ganesan, P.; Narayanasamy, D.; Sustain. Chem. Pharm. 2017, 6, 37.

70. Mehnert, W.; Mäder, K.; Adv. Drug Deliv. Rev. 2012, 64, 83.

71. Müller, R. H.; Radtke, M.; Wissing, S. A.; Adv. Drug Deliv. Rev. 2002, 54, 131.

72. Beloqui, A.; Solinís, M. Á.; Rodríguez-Gascón, A.; Almeida, A. J.; Préat, V.; Nanomedicine Nanotechnology, Biol. Med. 2016, 12, 143.

73. Faraday, M.; Philos. Trans. R. Soc. London 1857, 147, 145.

74. Kim, J. J. S. J. H.; Kuk, E.; Yu, K. N.; Kim, J. J. S. J. H.; Park, S. J.; Lee, H. J.; Kim, S. H.; Park, Y. H. Y. K.; Park, Y. H. Y. K.; Hwang, C. Y.; Kim, Y. K.; Lee, Y. S.; Jeong, D. H.; Cho, M. H.; Yu, N.; Kim, J. J. S. J. H.; Park, S. J.; Lee, J.; Kim, H.; Park, Y. H. Y. K.; Park, H.; Hwang, C. Y.; Kim, Y. K.; Lee, Y. S.; Jeong, D. H.; Cho, M. H.; Nanomedicine Nanotechnology, Biol. Med. 2007, 3, 95.

75. Wierzbinski, K. R.; Szymanski, T.; Rozwadowska, N.; Rybka, J. D.; Zimna, A.; Zalewski, T.; Nowicka-bauer, K.; Malcher, A.; Krupinski, M.; Fiedorowicz, M.; Bogorodzki, P.; Grieb, P.; Sci. Rep. 2018, 1.

76. Smijs, T. G.; Pavel, S.; Nanotechnol. Sci. Appl. 2011, 4, 95.

77. Salvioni, L.; Rizzuto, M. A.; Bertolini, J. A.; Pandolfi, L.; Colombo, M.; Prosperi, D.; Cancers (Basel) 2019, 11.

78. Wolfram, J.; Ferrari, M.; Nano Today 2019, 25, 85.

79. Dickinson, A. M.; Godden, J. M.; Lanovyk, K.; Ahmed, S. S.; Appl. Vitr. Toxicol. 2019, 5, 114.

80. Basavaraj, S.; Betageri, G. V.; Acta Pharm. Sin. B 2014, 4, 3.

81. Amidon, G. L.; Lennernäs, H.; Shah, V. P.; Crison, J. R.; Pharm. Res. 1995, 12, 413. 
82. Coukell, A. J.; Plosker, G. L. L.; Pharmacoeconomics 1998, 14, 691.

83. Bandak, S.; Ramu, A.; Barenholtz, Y.; Gabizon, A.; Pharm. Res. 1999, 16,841 .

84. Agência Nacional de Vigilância Sanitária (ANVISA); Agência Brasileira de Desenvolvimento Industrial (ABDI) Registro de Produtos Biologicos e Hemoterápicos. Bases Legais - Coletânea; 2011.

85. Blackman, L. D.; Varlas, S.; Arno, M. C.; Houston, Z. H.; Fletcher, N. L.; Thurecht, K. J.; Hasan, M.; Gibson, M. I.; O’Reilly, R. K.; ACS Cent. Sci. 2018, 4, 718.

86. Gu, Z.; Biswas, A.; Zhao, M.; Tang, Y.; Chem. Soc. Rev. 2011, 40, 3638.

87. de Brito, A. E. M.; Pessoa, A.; Converti, A.; Rangel-Yagui, C. de O. de O.; da Silva, J. A.; Apolinário, A. C.; Pessoa-Jr, A.; Converti, A.; RangelYagui, C. de O. de O.; da Silva, J. A.; Apolinário, A. C.; Mater. Sci. Eng. C 2019, 98, 524 .

88. Tokatlian, T.; Segura, T.; Talar Tokatlian; Segura, T.; Tokatlian, T.; Segura, T.; Wiley Interdiscip Rev Nanomed Nanobiotechnol. 2010, 2, 305 .

89. Ferrari, M.; Trends Biotechnol. 2010, 28, 181

90. Khallaf, R. A.; Salem, H. F.; Abdelbary, A.; Khallaf, R. A.; Salem, H. F.; Abdelbary, A.; Drug Deliv. 2016, 7544.

91. Mozafari, M.; Mol. Ther. 2018, 26, 2085.

92. Vogt, A.; Wischke, C.; Neffe, A. T.; Ma, N.; Alexiev, U.; Lendlein, A.; J. Control. Release 2016, 242, 3.

93. Mojeiko, G.; de Brito, M.; Salata, G. C.; Lopes, L. B.; Int. J. Pharm. 2019, $560,365$.

94. Lee, O.; Ivancic, D.; Chatterton, R. T.; Rademaker, A. W.; Khan, S. A.; Breast Cancer Targets Ther. 2011, 3, 61.

95. Palmer, B.; DeLouise, L.; Molecules 2016, 21, 1719.

96. Palmer, B. C.; DeLouise, L. A.; Molecules 2016, 21, 7.

97. Barry, B. W.; Adv. Drug Deliv. Rev. 2002, 54, 31.

98. Roberts, M. S.; Mohammed, Y.; Pastore, M. N.; Namjoshi, S.; Yousef, S.; Alinaghi, A.; Haridass, I. N.; Abd, E.; Leite-Silva, V. R.; Benson, H. A. E.; Grice, J. E.; J. Control. Release 2017, 247, 86.

99. Dragicevic, N.; Maibach, H.; Adv. Drug Deliv. Rev. 2018, 127, 58.

100. Nornoo, A. O.; Zheng, H. A.; Lopes, L. B.; Johnson-Restrepo, B.; Kannan, K.; Reed, R.; Eur. J. Pharm. Biopharm. 2009, 71, 310.

101. Pooja, D.; Kulhari, H.; Kuncha, M.; Rachamalla, S. S.; Adams, D. J.; Bansal, V.; Sistla, R.; Mol. Pharm. 2016, 13, 3903.

102. Lopes, M. A.; Abrahim, B. A.; Cabral, L. M.; Rodrigues, C. R.; Seiça, R. M. F.; de Baptista Veiga, F. J.; Ribeiro, A. J.; Nanomedicine Nanotechnology, Biol. Med. 2014, 10, 1139.

103. Shan, W.; Zhu, X.; Tao, W.; Cui, Y.; Liu, M.; Wu, L.; Li, L.; Zheng, Y.; Huang, Y.; ACS Appl. Mater. Interfaces 2016, 8, 25444.

104. Tetro, N.; Moushaev, S.; Rubinchik-Stern, M.; Eyal, S.; Pharm. Res. 2018, 35.

105. Joshi, M. D.; Ther. Deliv. 2017, 8, 1023.

106. Valero, L.; Alhareth, K.; Gil, S.; Lecarpentier, E.; Tsatsaris, V.; Mignet, N.; Fournier, T.; Andrieux, K.; Drug Discov. Today 2018, 23, 1099.

107. Abd-Ellah, N.; Taylor, L.; Troja, W.; Owens, K.; Ayres, N.; Pauletti, G.; Jones, H.; PLoS One 2015, 10, 1.
108. Bajoria, R.; Fisk, N. M.; Contractor, S. F.; J. Clin. Endocrinol. Metab. 1997, 82,3271 .

109. Wolburg, H.; Lippoldt, A.; Vascul. Pharmacol. 2002, 38, 323.

110. Patel, M. M.; Patel, B. M.; CNS Drugs 2017, 31, 109.

111. Vieira, D. B.; Gamarra, L. F.; Int. J. Nanomedicine 2016, 11, 5381.

112. Saraiva, C.; Praça, C.; Ferreira, R.; Santos, T.; Ferreira, L.; Bernardino, L.; J. Control. Release 2016, 235, 34.

113. Yameen, B.; Choi, W. Il; Vilos, C.; Swami, A.; Shi, J.; Farokhzad, O. C.; J. Control. Release 2014, 190, 485.

114. Walczyk, D.; Bombelli, F.; Monopoli, M.; Lynch, I.; Dawson, K.; J. Am. Chem. Soc. 2010, 132, 5761.

115. Panzarini, E.; Mariano, S.; Carata, E.; Mura, F.; Rossi, M.; Dini, L.; Int. J. Mol. Sci. 2018, 19, 2 .

116. Gaitzsch, J.; Appelhans, D.; Gräfe, D.; Schwille, P.; Voit, B.; Chem. Commun. 2011, 47, 3466.

117. Liu, F.; Kozlovskaya, V.; Medipelli, S.; Xue, B.; Ahmad, F.; Saeed, M.; Cropek, D.; Kharlampieva, E.; Chem. Mater. 2015, 27, 7945.

118. Mura, S.; Nicolas, J.; Couvreur, P.; Nat. Mater. 2013, 12, 991.

119. Deng, Y.; Ling, J.; Li, M. H.; Nanoscale 2018, 10, 6781.

120. Gruner, B. A.; Weitman, S. D.; Invest. New Drugs 1998, 16, 205.

121. Daniels, T. R.; Bernabeu, E.; Rodríguez, J. A.; Patel, S.; Kozman, M.; Chiappetta, D. A.; Holler, E.; Ljubimova, J. Y.; Helguera, G.; Penichet, M. L.; Biochim. Biophys. Acta, Gen. Subj. 2012, 1820, 291.

122. Frenz, T.; Grabski, E.; Durán, V.; Hozsa, C.; Stępczyńska, A.; Furch, M.; Gieseler, R. K.; Kalinke, U.; Eur. J. Pharm. Biopharm. 2015, 95, 13.

123. Hayward, S. L.; Wilson, C. L.; Kidambi, S.; Oncotarget 2016, 7.

124. Sun, H.; Dong, Y.; Feijen, J.; Zhong, Z.; J. Control. Release 2018, 290, 11

125. Contini, C.; Nyberg, S.; Azizi, J.; Battaglia, G.; Tian, X.; Fullstone, G.; Joseph, A.; Volpe, G.; Gaitzsch, J.; Preston, J.; Ruiz-Perez, L.; Cecchin, D.; Sci. Adv. 2017, 3, e1700362.

126. Food and Drug Administration; Liposome Drug Products: Chemistry, Manufacturing, and Controls; Human Pharmacokinetics and Bioavailability; and Labeling Documentation.; 2018.

127. European Medicine Agency; Reflection paper on non-clinical studies for generic nanoparticle iron medicinal product applications, 2011.

128. European Medicine Agency; Joint MHLW/EMA reflection paper on the development of block copolymer micelle medicinal products, 2013.

129. European Medicine Agency; Reflection paper on surface coatings : general issues for consideration regarding parenteral administration of coated nanomedicine products, 2013.

130. European Medicine Agency; Reflection paper on the data requirements for intravenous liposomal products developed with reference to an innovator liposomal product, 2013.

131. EMA/CHMP/CMDh; Names of liposomal medicines to be changed to avoid medication errors, disponível em https://www.ema.europa.eu/en/ news/names-liposomal-medicines-be-changed-avoid-medication-errors, acessada em Janeiro 2020.

132. Wibroe, P. P.; Ahmadvand, D.; Oghabian, M. A.; Yaghmur, A.; Moghimi, S. M.; J. Control. Release 2016, 221, 1 . 